Portland State University

PDXScholar

\title{
Transformative Health Care: Integrating the Perspectives and Lived Experiences of Transgender and Gender Diverse Patients into Health Care Education and Delivery
}

Shammarie Raquel Mathis

Portland State University

Follow this and additional works at: https://pdxscholar.library.pdx.edu/open_access_etds

Part of the Anthropology Commons, and the Lesbian, Gay, Bisexual, and Transgender Studies Commons

Let us know how access to this document benefits you.

\section{Recommended Citation}

Mathis, Shammarie Raquel, "Transformative Health Care: Integrating the Perspectives and Lived Experiences of Transgender and Gender Diverse Patients into Health Care Education and Delivery" (2021). Dissertations and Theses. Paper 5718.

https://doi.org/10.15760/etd.7591

This Thesis is brought to you for free and open access. It has been accepted for inclusion in Dissertations and Theses by an authorized administrator of PDXScholar. Please contact us if we can make this document more accessible: pdxscholar@pdx.edu. 
Transformative Health Care: Integrating the Perspectives and Lived

Experiences of Transgender and Gender Diverse Patients into Health Care Education and Delivery

by

Shammarie Mathis

A thesis submitted in partial fulfillment of the Requirements for the degree of

Master of Arts
in
Anthropology

Thesis Committee:

Charles Klein, Chair

Miriam Abelson

Jeremy Spoon

Christina Sun

Portland State University

2021 


\begin{abstract}
Prior research studies have found transgender and gendernon-conforming (TGNC) patients at increased risk for poor physical and mental health as a result of disparities in health care access and treatment (Giffort, 2016; Grant et al., 2011; James et al., 2016). Research has shown that perioperative patient education can improve patient outcomes, as well as promote increased knowledge, preparedness, and recovery post-surgery (Poceta et al., 2019). For TGNC patients, gender affirming perioperative education classes are especially important for prospective patients as they not only provide comprehensive information about perioperative topics but also serve as a mechanism to promote personal empowerment through knowledge acquisition. The Oregon Health and Science University (OHSU) Transgender Health Program (THP) is currently utilizing this approach to patient education for TGNC communities. However, due to limited staffing and bandwidth, the THP has not been able to update the curriculum to reflect the priorities and needs of gender-affirming surgery patients.
\end{abstract}

The method of knowledge dissemination is of paramount importance, especially when engaging with historically marginalized populations. Developing health educational materials in collaboration with patients increases the relevancy of the content presented, as it reflects the values and priorities of the communities involved. For TGNC individuals, such insight will result in curriculums that are sensitive to, and affirming of, the identities of patients who are in process of navigating gender 
transition. Additionally, updating the curriculum could help reduce postoperative patient complications by presenting material that is highly relevant to the patient while simultaneously promoting self-empowerment through knowledge acquisition. The goal of this collaborative project is to develop recommendations to update the curriculums of current genital gender-affirming surgery (GGAS) classes to promote patient preparedness, learning, empowerment, and identity affirmation. Utilizing critical approaches to research, patient and provider knowledge as well as embodied experience will inform the development of curriculum recommendations. I will accomplish this endeavor by leveraging a transformative mixed-methods sequential design study using both quantitative and qualitative data collection tools. Such tools will incorporate various analytical approaches to assessing data, including survey analysis and qualitative interviews. Integrating these data will provide a comprehensive understanding of the various and nuanced needs of TGNC patients. As such, critical theories and methodologies can help devise a patient education curriculum that is both transformative, while also avoiding and/or mitigating harmful messages that disenfranchise or perpetuate forms of oppression (e.g., transnormativity) (Ferguson, 2013). 


\section{Table of Contents}

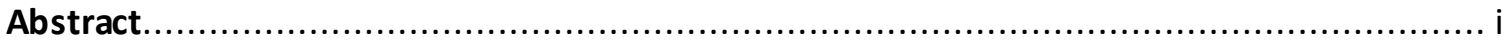

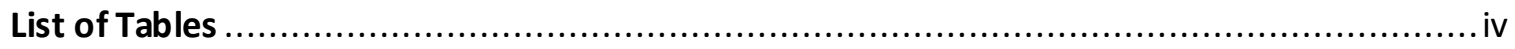

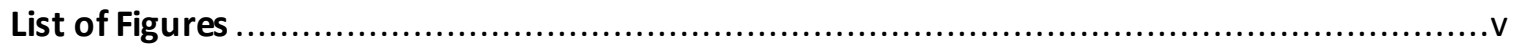

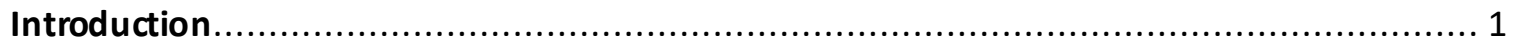

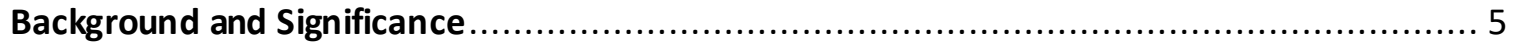

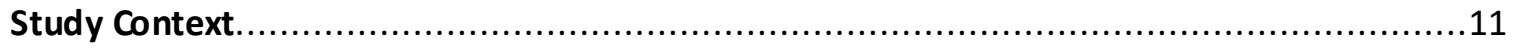

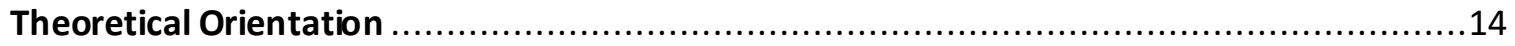

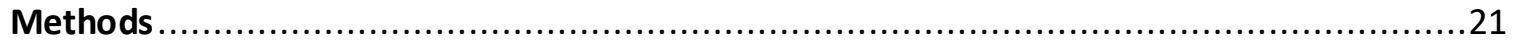



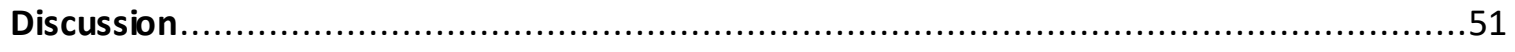

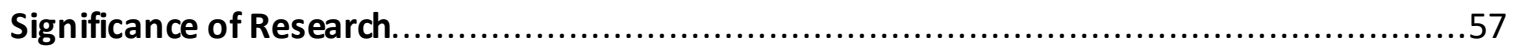

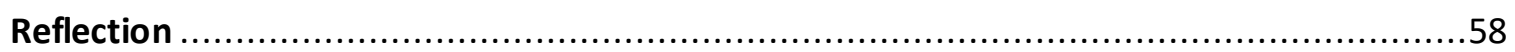

Table 1. Participant Demographics - Qualitative Interviews ....... Error! Bookmark not defined.

Figure 1. Approach toward Integrating Analytical Findings........ Error! Bookmark not defined.

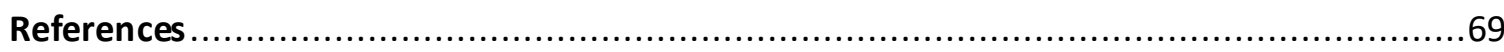

Appendix A. GAS - Patient Education Classes Feedback and Evaluation Form..................74

Appendix B. Participant Screening Tool for Qualitative Interviews .............................77

Appendix C. Phase 2 Qualitative Interview Guide............................................ 78 


\section{List of Tables}

Table 1. Participant Demographics - Qualitative Interviews 


\section{List of Figures}

Figure 1. Approach toward Integrating Analytical Findings 


\section{Introduction}

The year 2021 has already been a challenging year for transgender and gender nonconforming (TGNC) people as state laws across the country seek to eradicate protections for this group. Although meaningful advancements have been made in terms of providing medical coverage for gender-affirming health care, access to such care remains a challenge for many TGNC people, especially for those seeking gender-affirming surgery (GAS). For those who are able to access surgery, patient education classes are sometimes offered as a means to prepare patients for the surgical process. Prior studies have indicated the effectiveness of these classes for GAS patients (Poceta et al., 2019). However, these classes have been conventionally taught from the perspective of surgeons and health care administrators, many of whom have not personally experienced GAS.

Living through the experience of GAS is unique in that the physical transformation intersects with that of social, mental, and emotional transformations as well. Prior patients of GAS not only offer great insight into the short- and long-term implications of undergoing surgery, but can also provide a basis of knowledge that is currently lacking in patient education. Examples of such knowledge include post-surgical complications, the unforeseen social impacts of undergoing GAS, as well as long-term aftercare practices not commonly discussed in general GAS discourse.

The Oregon Health and Science University (OHSU) Transgender Health Program (THP) is a coordinating and support center specifically catering to TGNC patients. As a program, the THP provides a vast array of services, including connecting patients with providers, supporting community outreach programs, as well as providing educational classes intended for patients and providers. Currently, the OHSU THP is in-process of updating the curriculums for their 
genital gender-affirming surgery (GGAS) patient education classes (e.g., phalloplasty/metoidioplasty and vaginoplasty/vulvoplasty). As part of this initiative, I worked in partnership with the OHSU THP to develop a patient-centered approach toward updating the curriculums, incorporating the experiences, needs, and priorities of patients who are at any stage of considering GGAS.

To effectively understand the unique needs and experiences of TGNC patients, this project utilized theoretical approaches that examined the interplay of power and marginalization within the health care setting. The transformative paradigm and discursive aggression are appropriate in this circumstance as each theory assesses how power imbalance within institutional settings create marginalization and self-policing, contextualizing this predicament within the framework of oppression. Queer of Color (QOC) Critique provides a basis to understand the social and historical forces that create marginality, and how this marginality affects how students engage in the transmission and production of knowledge within the educational setting. This approach is likewise useful to develop approaches toward destabilizing entrenched power structures within the education setting, moving to legitimate lived experience as a valid form of knowledge. As such, identities - especially for queer people of color - become affirmed through the politics of visibility.

This project utilized a multi-phased approach to collect data, which included a mixedquantitative-qualitative analysis of feedback and evaluation forms, as well as qualitative interviews with OHSU THP patients. Each set of results were then cross-compared with one another, where overarching themes emerged. These themes related to the various experiences patients encounter across the surgical trajectory of GGAS, as identified by participants. For example, participants spoke of the disjunction between the accessibility of health care coverage 
for gender-affirming care, yet the dearth of providers available to provide such care. Other participants described their experiences of wanting to give up pursuing gender-affirming surgery due to adversities encountered during the process. Participants likewise identified approaches and resources that would help mitigate or lessen the impact of these circumstances. Such approaches include prioritizing patients educating fellow patients, as well as providing support systems for those who require it once the decision to have GGAS is made.

Results from this project indicate a current gap in patient education for GGAS, emphasizing the need for integrating the patient perspective into future curriculums. Further, GGAS patients may require additional resources to help them navigate the surgical process. This is especially important for TGNC patients, who typically encounter many adversities in their daily lives outside the health care setting. Integrating patient perspectives into educational settings will likely increase the relevance of the material, inform surgical choices, better prepare patients both short- and long-term, as well as serve as an example to patients as to what is feasible postsurgery. In turn, establishing resources such as support systems may help educate patients as well as aid them throughout the surgical trajectory, providing a means for knowledge sharing and establishing peer support.

Findings from this study will inform how the OHSU THP will update the curriculums for GGAS patient education classes. Recommendations deriving from participants' reported experiences will serve as the basis for updating the content. For example, future GGAS patient education classes should emphasize long-term aftercare needs that are not often discussed in common GGAS discourse. Further, these findings will support arguments for establishing additional resources for THP patients. This includes having either the OHSU THP or another entity host a support group for prospective or current patients of GGAS. These 
recommendations will inevitability enable the OHSU THP to better support their patients, as well as promote patient education and self-determination as they navigate the process of undergoing GGAS. 


\section{Background and Significance}

Current estimates suggest that approximately 1 million individuals identify as transgender in the United States, representing $0.5 \%$ of the total population (Flores et al., 2016); however, this may be an underestimation, with some researchers proposing the population to be closer to $2 \%$ (Doan, 2016). Here, transgender is an allencompassing term used to describe individuals who "have gender identities, expressions, or behaviors not traditionally associated with their birth sex" (Gender Education and Advocacy, 2001). Many TGNC patients seek medical and/or surgical gender-affirming care to express their gender identity, while other patients may not desire hormonal or surgical treatment. Common gender-affirming procedures include surgical (e.g., metoidioplasty/phalloplasty, top/chest surgery, and vulvoplasty/vaginoplasty) and hormonal (e.g., hormone replacement therapy) interventions.

Prior research studies found TGNC individuals at increased risk for poor physical and mental health as a result of disparities in health care access and treatment (Giffort, 2016; Grant et al., 2011; James et al., 2016). For example, approximately 39\% of respondents for the 2015 U.S. Transgender Survey (USTS) reported experiencing psychological distress; a rate nearly eight times the rate of the U.S. population (James et al., 2016). Other studies have found TGNC individuals to be at increased risk for substance use disorder (SUD), non-medical prescription drug use, and self-harm (Benotsch et al., 2011; Brown \& Jones, 2014; Dragon et al., 2017; 
Meyer et al., 2017; Poceta et al., 2019). Further, TGNC individuals encompassing multiple marginalized identities (e.g., racial/ethnic) are at a higher risk for experiencing health disparities. In a study conducted by Brown and Jones, black transgender veterans were found to be at increased odds to be diagnosed with alcohol misuse, congestive heart failure, serious mental illness, tobacco use, and hypertension, among other comorbidities (Brown \& Jones, 2014). From these examples, it becomes clear that patient education is one among many interventions within the framework of health systems as it helps to mitigate some of the effects of health disparities.

Research has shown that perioperative patient education can improve patient outcomes, as well as promote increased knowledge, preparedness, and recovery post-surgery (Poceta et al., 2019). For TGNC patients, gender-affirming perioperative education classes are especially important for prospective patients as they not only provide comprehensive information about perioperative topics but also serve as a mechanism to promote personal empowerment through knowledge acquisition. In one study examining the effectiveness of GAS patient education classes for TGNC patients, participants reported feeling betterinformed about their surgical options, were more prepared for their surgery, better informed about possible complications, and better understood their postoperative care needs (Poceta et al., 2019). Feeling prepared for the serious reality of surgery is fundamental to TGNC patient empowerment and agency as it provides a sense of control over one's body, health, 
and care trajectory. Other research on perioperative patient education classes have likewise reported positive outcomes, including improved long-term symptom management, alleviating health care system burdens, and increased feelings of empowerment and agency among patients and caregivers (Petersen, 2008). Thus, perioperative patient education classes are vital to improved symptom management, postoperative outcomes, and other related outcomes for patients.

Oregon Health \& Science University's (OHSU) Transgender Health Program (THP) recognizes the importance of providing safe, comprehensive, and affirming care for TGNC communities. The primary endeavor of the program is to improve the community's overall wellbeing through education, research, and leadership that responds to the healthcare needs of TGNC individuals. Once monthly, the THP offers gender-affirming patient education classes for patients at any stage of considering their surgery. Each session addresses several aspects of the surgery process, including perioperative health and wellness; surgical options and how to choose; what to expect from surgery; and postoperative recovery. Curriculums for each session are consistent throughout; however, information regarding surgery options are tailored for the intended audience. Due to limited staffing and bandwidth, the THP has not been able to update the curriculum to reflect current priorities and needs of GAS patients, as well as address opportunities for improvement as indicated by patients. Updating the curriculum could help reduce postoperative patient complications by presenting material that is highly relevant to the patient thus increasing uptake, while 
simultaneously promoting self-empowerment through knowledge acquisition.

Another beneficial quality of gender affirming patient education classes is their ability to educate and prepare providers to competently treat their patients. According to the National Transgender Discrimination Survey, approximately $50 \%$ of TGNC patients reported having to educate their providers about TGNC issues and care (Grant et al., 2011). Further, 23\% of TGNC patients reported not seeking medical care when they needed to because of fear of being mistreated as a TGNC person (James et al., 2016). This lack of provider knowledge and perpetual discrimination creates a sense of frustration and alienation among many TGNC patients, regardless of the intention of the medical provider. One study found that even providers who were committed to providing high-quality and culturally sensitive care to their patients did not feel prepared to treat TGNC patients (Lurie, 2005). This lack of uncertainty calls into question the provider's competence, which invariably will negatively affect the patient-provider relationship. Therefore, patient education classes provide a space where providers can become familiar with the specific health care needs of TGNC patients; this co-learning opportunity will assist health care providers in developing a sense of empowerment and agency when serving TGNC patients (Baker \& Beagan, 2014; Freire, 1970; Sprague et al., 2019).

Poor postoperative outcomes for gender affirming surgery (GAS) are common and include medical (e.g., thrombosis), functional (e.g., voiding problems), and aestheticissues (e.g., tissue necrosis) (van de Grift et al., 2017). In one study 
examining postoperative outcomes for GAS, progressive voiding disorder due to metal stenosis was found to be a primary complication observed in patients, affecting $40 \%$ of patients overall (Neto et al., 2012). The same study found occurrences of stricture of vaginal introitus (15\%), vaginal stenosis (12\%), and loss of vaginal depth (8\%) among patients (Neto et al., 2012). Such complications can temporarily affect postoperative patient satisfaction and quality of life (van de Grift et al., 2017). To date, only one study assessing the effectiveness of gender-affirming patient education classes for TGNC individuals exists. Within this study, patients reported that they were better informed about their surgical options, more prepared for surgery, better informed about possible complications, and better understood postoperative care needs (Poceta et al., 2019). This study is demonstrative of the potential power of gender-affirming patient education classes to help mitigate the effects of health disparities commonly experienced by TGNC individuals. Genderaffirming patient education classes are therefore a means to minimize potential postoperative complications through knowledge acquisition and personal exercises to encourage preemptive planning.

The method through which knowledge is disseminated is of paramount importance, especially when engaging with historically marginalized populations. Developing health educational materials in collaboration with patients increases the relevancy of the content presented, as it reflects the values and priorities of the communities involved. For TGNC people of color (POC), incorporating their 
perspectives and lived experiences into educational materials serves to recognize and affirm their intersectional identities and experiences. Further, using patients' lived experience as a primary source for knowledge production is a useful mechanism to undermine implicit modes of oppression dominant throughout health discourse (Brockenbrough, 2015; hooks, 1994). This is especially true for TGNC POC, who have been historically been pushed to the social margins. As an alternative pedagogical approach, Paulo Freire presented the concept of problem-posing education as a mechanism to understand human beings in relation to the world (Freire, 1970). Such an approach dismantles dichotomous learning apparatuses to develop opportunities of co-learning between educators and learners. This educational approach motivates individuals to become active and engaged learners; aware of their humanity while also cognizant that theirvoices deserve to be heard (Freire, 1970). A community-centered approach within patient education will result in curriculums that are both empowering and affirming of the intersectional identities of patients who are in process of navigating gender transition. Thus, it is imperative to develop educational tools that are highly relevant and culturally sensitive for the intended audience in order to improve postoperative health outcomes, patient wellbeing, and personal empowerment. 


\section{Study Context}

In 2015, OHSU founded the Transgender Health Program (THP) as a response to elevated requests for gender-affirming care within the Oregon and Southwest Washington regions. The OHSU THP provides safe, comprehensive, and affirming care for the TGNC communities. The THP Program Supervisor manages the program, in addition to three physicians with appointments at OHSU. Additionally, several community groups, including the THP Advisory Board, THP Community Meetings, and the THP Community Advisory Board guide the program. Both the THP Advisory Board and the THP Community Board consists of TGNC individuals who have received THP program services or who represent served communities. Members apply to serve two-year terms and membership fluctuates as community members enter and exit the program. Each board meets quarterly to advise the program about programs and services. THP Community Meetings are held on the third Wednesday of each month. Approximately 10-15 individuals from the TGNC and health care communities attend the meeting.

Following guidelines established by the World Professional Association for Transgender Health (WPATH), the THP offers culturally responsive medical care as part of OHSU's commitment to diversity and inclusion. This includes providing support, information, and advocacy for patients seeking gender-affirming care. The THP offers a wide array of services for patients, including assistance in arranging health care services, links to expert OHSU providers for health care needs, free 
classes and events on topics such as GAS, opportunities to become a volunteer or supporter, or training for OHSU employees and/or health care professionals in the community, among others. Since its inception, the program has served thousands of patients, trained thousands of health care providers across the region, and has expanded its offerings to include an array of medical specialists who are able to address the diverse needs of the community. In 2018, the program completed approximately 3,800 referrals/consultations and conducted 85 training sessions reaching 2,380 health care professionals in the Northwest region.

Currently, OHSU is one of few academic health centers in the United States to offergender-affirming care for individuals across the life span. The University does not have a single transgender clinic but instead offers a collection of primary care and specialty care clinics whose providers integrate gender-affirming medical and surgical care into their practices. Care clinics are located at the main OHSU Hospital, Doernbecher Children's Hospital, and the Richmond Clinic. Over 30 OHSU providers across the Northwest region offergender-affirming care to TGNC patients. However, the OHSU THP is experiencing budget difficulties as it seeks to expand staffing to address the growing need for gender-affirming services in the Northwest region. As such, the program has been unable to develop additional programs and services that would invariably improve both the THP and the service it provides to its patients. For example, due to limited bandwidth, the program has not been able to develop procedures to keep record of patients as they progress through the referral 
process. Such metrics could provide valuable data in terms of identifying patients who are "falling through the cracks" as they navigate through the program; additionally, the program can use this data to justify requests to increase the THP operating budget. 


\section{Theoretical Orientation}

Developing patient education curriculums intended for marginalized communities requires the use of critical methodologies and anthropological methods to understand their needs and priorities, as well as identify barriers to accessing care. Critical methodologies are analytical mechanisms designed to question and destabilize hegemonic power structures while also being critically reflexive and transformative in the pursuit of social justice. Such an approach is appropriate within the context of education within TGNC communities as it prioritizes the notion of intersectionality, positionality, and transgressive modes of knowledge production. To develop a patient education that is relevant to these communities, it is imperative to engage the community as part of the process. To critically evaluate the data acquired from this project, as well as develop recommendations oriented toward social justice, I will utilize three theoretical/methodological perspectives: transformative paradigm, discursive aggression, and queer of color critique. The following questions will guide this research project:

1. In the educational context, who creates knowledge? How does it create access and shape outcomes?

2. What unanticipated outcomes occur as a result of surgery and how do these outcomes shape experience?

3. How do patient education courses address contesting constructions of gender, including the notion of the "ideal" TGNC patient?

In partnership with the THP, we will use the data acquired from this project to develop recommendations to update the current genital genderaffirming surgery (GGAS) patient education curriculum. 


\section{Transformative Paradigm}

This project will employ a transformative mixed-method sequential design framework to collect data. This framework is predicated on the transformative paradigm, whose assumption rests on the recognition of power differences and the ethical implications that derive from those differences in terms of discrimination, oppression, misrepresentation, and creating a sense of marginalization (Canales, 2013; Mertens et al., 2015; Mertens et al., 2008; Romm, 2015). The paradigm recognizes the importance of contextual factors, such as social justice (or lack thereof), power, and oppression. Transgender and GNC communities continue to experience health disparities in health care access and treatment. For example, $23 \%$ of respondents from the 2015 USTS claimed that they did not seek medical help when they needed to due to fear of being mistreated as a transgender person (James et al., 2016). Established hierarchies and powerimbalances within the medical context have created an environment that is highly volatile for TGNC patients. These mechanisms of oppression continue to prevail throughout the health care system and may manifest in innocuous forms - in this case, gender-and other identity-affirmation in patient care (Crosby et al., 2016; Sevelius et al., 2016). Patient education curriculums have the potential to reinforce hierarchies, notions of the "ideal" patient, and serve to invalidate identities. As such, the transformative paradigm is a useful tool to understand prevailing oppressive structures as it holds the potential to contextualize these factors within the framework of social justice. 
Leveraging the transformative paradigm within a health education context will bring to light the various power systems functioning both within OHSU and the THP that affect TGNC patients as well as providers who provide gender-affirming care. I will use this approach to examine the felt effects of the curriculum upon patients and providers, whether the curriculum is reinforcing hierarchies (e.g., dichotomous patient-provider relationships), establishing the notion of the "ideal" TGNC patient, and if the curriculum serves to validate patients' various intersectional identities. Conducting survey analysis, content analysis, and semistructured qualitative interviews will allow me to understand how these contextual factors function to bring visibility to members of marginalized communities and whether current modes of patient and provider education unintentionally creates forms of oppression.

\section{Discursive Aggression}

The concern over affirmation and representation within educational curriculums demonstrate how discursive factors shape social interactions. Discursive aggression is a concept used to describe how communicative acts are leveraged in social interactions to hold people accountable to social and cultural-based expectations, and how individuals hold themselves accountable in anticipating the expectations of others (Hollander, 2013; Shuster, 2017). Communicative acts are thus a means to implement expectations or to restore order in interaction. Language 
structures within medicine has historically adhered to a gender binary system that has the potential to affect the presentation and performance of patients in their pursuit of accessing care (Spade, 2003, 2015). When the system of inequality is destabilized by non-normative identity presentations (e.g., TGNC), those in power (e.g., administrators, care providers) may feel entitled to re-stabilize the situation by regulating others to uphold the social order (Shuster, 2017). In the context of patient education classes for TGNC communities, discursive aggression may unintentionally manifest through mechanisms of identity invalidation.

The TGNC communities are diverse; identities continue to develop as individuals become further aware of the fluid nature of genderidentity (Butler, 1990). Prior research studies have attempted to capture the array of identities that fall under the umbrella of TGNC (Grant et al., 2011; James et al., 2016); however, neither medical nor patient educational interventions have been successful in addressing the multiplicity of identities that fall within the TGNC spectrum. When educational interventions fail to validate or inappropriately assign identity, they may cause TGNC individuals to feel that they are not being received in ways they wish to be known, are being made invisible, and that their agency in self-naming and claiming a gender identity is invalid (Shuster, 2017). Additionally, the binary system of gender identity shapes gender expectations as well as the conceptualization of what it means to be transgender.

TGNC individuals who do not fit the dominant narrative of "transgender" (e.g., 
transitioning from one gender to the other) are sometimes regulated and invalidated by both the institution and other transgender individuals (Shuster, 2017; Spade, 2003). For example, non-binary individuals continue to face slights as they negotiate both a structure of language that organizes gender into a normative framework that defines who qualifies as transgender. Further, TGNC individuals may engage in selfsilencing to uphold social order. This approach, in addition to identity invalidation, may cause TGNC individuals to feel a sense of disempowerment and a loss of agency over their own health care while navigating transition. As institutions continue to perpetuate inequality and restrict TGNC individuals, discursive aggression becomes a mechanism to regulate these communities through everyday interactions.

\section{Queer of Color Critique}

Agency in navigating the myriad challenges throughout transition poses potential for resistance against intersecting arrangements of power in medicine. Queer of Color (QOC) Critique offers an intersectional and interdisciplinary approach to unveil the social and historical forces that produces QOC marginality (Brockenbrough, 2015; Ferguson, 2018; Johnson, 2016; Winkle-Wagner et al., 2019). Within patient education, QOC critique allows analyses of health care and educational contexts to consider how various bodies of knowledge have produced QOC invisibility and pathology, and provides an important backdrop for closer examinations of how queer students of color engage in the transmission and production of knowledge in 
educational settings (Brockenbrough, 2015). QOC critique is also a useful tool in exposing how systems of regulation promote racialized and patriarchal discourses of sexual normativity (Ferguson, 2018; Johnson, 2016). TGNC individuals are more than just theirgender identity; they, like others, encompass a multiplicity of identities that shape their lived experiences. By contextualizing TGNC identities within QOC difference, QOC critique holds the potential to engage new ways of knowing and being that can inform recommendations to develop patient education curriculums that are inclusive and affirming of intersectional identities.

Given the hegemonic nature of educational contexts and its focus to disseminate socially-acceptable forms of knowledge, it is imperative to identify strategies to support the intellectual agency of queers of color (Brockenbrough, 2015). Most traditional teaching models rely upon a "banking system" of learning, whereas learners are not part of the process of knowledge production but are rather passive subjects throughout the learning process (Freire, 1970; hooks, 1994). This approach establishes a hierarchy wherein the production of knowledge is entirely reserved for those in power; within this context, the power lies with the medical institution and administrators. Foucault presented knowledge as inextricably enmeshed in relations of power because it is constantly being applied to the regulation of social conduct in practice (Foucault, 1980). When devising patient educational curriculums for individuals embodying multiple marginalized identities (e.g., TGNC, QOC), it is imperative destabilize these power structures by incorporating 
the intersectional nature of QOC lived experience as a source of knowledge. In doing so, QOC identities become affirmed through the politics of visibility. 


\section{Methods}

Given the various sources of data for this project, I felt it was best to approach data collection utilizing a multi-phased process. In total, there were four phases that comprised the project:

- Phase 1: Analyze feedback and evaluation forms from the GGAS patient education classes

- Phase 2: Semi-structured qualitative interviews with THP patients

- Phase 3: Integrate analytical findings

- Phase 4: Develop curriculum recommendations and results dissemination

Phase 1: Analyze feedback and evaluation forms from the GGAS patient education classes

In June 2020, I began Phase 1 of the project by meeting with the THP Program Administrator to clarify their expectations of the project, as well as obtain paper copies of the feedback and evaluation forms. Given the popularity of some classes over others, the Program Administrator decided it was best to focus the project on updating the curriculums for the GGAS classes (phalloplasty/metoidioplasty and vaginoplasty/vulvoplasty). Historically, top surgery classes have had low attendance rates. Further, there has and continues to be a more pronounced need for updating the GGAS classes as the demand for GGAS continues to increase over time. We both agreed to this modification to the original study, and I proceeded accordingly.

Over the course of the GGAS class' existence, data for the classes has been collected through hard copies, which were then filled out and returned by the participant. Given this predicament, I felt it was best to capture the data in a database 
where it would be easierfor me to pull data queries during the analysis phase. I thus developed a REDCap database, which would not only capture data from the feedback and evaluation forms but would serve as a tool for future participant recruitment as well. The data collection tool I developed for this phase directly mirrored that of the feedback and evaluation forms filled out by participants (Appendix A). The form includes both quantitative and short-answer qualitative components, which I expected would provide meaningful evaluative data derived from the participant's reported experience of the class. Evaluation metrics included topics/sessions participants enjoyed, opportunities for improvement(s), topics participants would like to see in future classes, and the most important takeaway lessons learned during class. Unfortunately, the form did not include a section to collect participant demographic data, which meant I would have to report results in aggregate form.

The date range of the forms spanned from late 2017 to early 2020, with the last batch of forms originating from classes held in February 2020. In total, I captured data from 357 feedback and evaluation surveys (166 phalloplasty/metoidioplasty, 190 vaginoplasty/vulvoplasty, and 1 unknown class). Due to the pandemic, the THP temporarily suspended classes. This meant that I did not have any new data beyond February 2020. Classes have not resumed to-date as the THP continues to update the curriculums and move their classes to a more accessible online platform. Once all data was entered into the REDCap database, I proceeded with analyzing the data utilizing both qualitative and qualitative approaches. For the quantitative portion, I quickly 
learned and applied the software program SPSS. For qualitative, I used NVivo 11 software (QSR International, 2015) to assess open-ended responses. Once I concluded analysis, I developed a short summary of results to inform Phase 2 of the project, where I would develop an interview guide.

\section{Phase 2: Semi-structured qualitative interviews with THP patients}

Due to logistical limitations, I was not able to initiate Phase 2 of the study until October 2020. These limitations primarily related to how the THP and I would approach participant recruitment. After some discussion, the Program Administrator and I agreed that it would be best that I contact participants using the shared OHSU THP email inbox. We thought this approach would both grant name recognition and credibility to the project as prospective and prior THP patients would be more likely to open an email originating from the OHSU THP email account. However, accessing the inbox required that I obtain departmental approval, which proved to be a minor logistical barrier during the process. First, neither of us were entirely sure which process we needed to pursue to grant me approval. After some trial and error and many questions asked of OHSU's Information Technology department, I was finally able to gain access to the shared inbox. While waiting for approval, I utilized this time to work with the Program Administrator on a recruitment letter that I would send from the THP email account. I produced the initial draft, while the Program Administrator refined the language in the draft for readability and to appeal to a wider audience of potential participants. To 
efficiently capture and organize participant data, I decided to develop a screening tool in REDCap for interested participants to fill out. This tool asked participants to provide contact information, as well as basic demographic variables (Appendix B). Demographic variables included in this tool included age rage, gender identity, ethnicity, education level, among others. The REDCap link for this screening tool was included in the final version of the participant recruitment letter.

Unexpectedly, a significant development occurred once I was on the cusp of sending out the recruitment letter. During one of my routine meetings with the Program Administrator, I was introduced to a relatively new OHSU surgeon who is likewise interested in conducting research on GGAS and patient experiences. Dr. Surgeon works at OHSU, with a specialty in performing genital gender-affirming surgery. During our meeting, I discussed my project with Dr. Surgeon, giving them a basic overview of the project as well as outlined anticipated timelines. At the conclusion of the meeting, Dr. Surgeon expressed their interest in the project, noting how the results from this project would help inform their own research pending research projects and grant submissions. Upon furtherdiscussion, Dr. Surgeon offered to fund the purchase of the gift cards to reimburse participants ( $\$ 50 /$ interview), as well as provide me with a comprehensive contact list of their current and former patients. Dr. Surgeon thus became an additional stakeholder in the project, whose input I incorporated into the research design.

By late October 2020, I was finally able to begin participant recruitment for this phase. The email lists I used derived from email addresses of GGAS class attendees that I 
extracted from the feedback and evaluation forms from Phase 1, as well as Dr.

Surgeon's comprehensive list of current and former patients. To enhance the diversity of perspectives and experiences offered by participants, we identified three distinct groups for inclusion:

- THP patients who did not attend the GGAS patient education class, but have completed GGAS

- THP patients who attended the GGAS patient education class, but have not completed GGAS

- THP patients who attended the GGAS patient education class and have completed GGAS.

Originally, our goal was to recruit 3 participants representing each surgery subgroup (phalloplasty/metoidioplasty or vaginoplasty/vulvoplasty) within these overarching groups. In total, I had anticipated recruiting 18 individuals for this phase. Although I had reservations about the feasibility of recruiting 18 individuals, these reservations were soon put to rest when I quickly witnessed an enthusiastic response to the project. In total, we had 52 submissions from interested individuals, far exceeding the amount of space we had available for interviews. As such, I decided to expand the number of interviews, recruiting 4 participants representing each surgery subgroup and totaling 24 participants.

When scheduling interviews, I utilized the approach of purposeful sampling to allow for the assimilation of rich information within a context of limited resources. As such, I referred to the demographic information that participants provided through the REDCap screening tool. To ensure the final results represented a diversity of perspectives and life experiences, I prioritized scheduling black, indigenous and people 
of color (BIPOC) submissions. Afterward, I scheduled participants using other demographic variables (e.g., educational background, geographiclocation, age range, insurance status, etc.), ensuring a wide array of experiences. I found that one group in particular was difficult to recruit, despite my focused efforts on reaching this population. Specifically, I had trouble recruiting individuals who attended the GGAS patient education class, but had not completed phalloplasty/metoidioplasty GGAS. When I asked the THP Program Administratorabout the difficulty in reaching this group, they thought that this may have to do with the fact that phalloplasty/metoidioplasty had a higher completion rate compared to vaginoplasty/vulvoplasty. As a result, I was only able to recruit 1 person representing this group. Further, another participant mistakenly misreported their surgery status in the screening tool. I had already scheduled this participant for an interview, and therefore re-assigned them to another (already full) group.

Sample

The final sample consisted of 22 individuals, representing diverse backgrounds (Table 1). Three identified themselves as Hispanic/Latinx, two as Asian, three as Native American, one as Black/African, four as mixed race, and nine as white. Participants reported a range of educational backgrounds, ranging from having completed high school, to completing college or beyond. They likewise represented a diverse age range, spanning from 19 to 72 years old. Gender identities were not as diverse, with nine 
reporting as male, eight reporting as female, three reporting as trans woman, one as intersex, and one as female-presenting non-binary. Table 1 summarizes additional participant characteristics. Although this sample is diverse, its relatively small size and regional specificity does not make it representative of the varied experiences of all TGNC individuals. However, the various backgrounds and lived experiences of participants that were part of this project lent meaningful insight into the complexities of accessing GGAS.

\section{Data Collection}

In partnership with the THP Program Administratorand Dr. Surgeon, I developed an interview guide containing probes that reflected the unique experiences of the three overarching groups included in the study (Appendix C). The interview guide contained open-ended questions, allowing participants to reflect upon their experience(s) as patients who have accessed gender-affirming care. Each interview began with the prompt, "Tell me about your experiences in accessing gender-affirming care." This question served as both an icebreaker, and as a means to contextualize selfreported experiences later in the interview. Topics covered during the interview included: perceptions of patient preparedness for GGAS, feelings and/or perceptions about curriculum messaging, and whether in-person efforts effectively improved preparedness for surgery and improving overall post-surgical outcomes. Throughout the interviews, I maintained a notebook consisting of field notes and other ideas that 
emerged during the research process. These notes were later used as a reference during qualitative analysis.

One byproduct of including an additional stakeholder in this project was that my semi-structured interview guide became less semi- and more highly-structured after the project stakeholders had an opportunity to submit their edits. Understandably, both stakeholders had very specificinterests in the project, each wanting to gain insight into topics that were of particular interest to their own professional endeavors. Specifically, the Program Administrator wanted comprehensive information about participant experiences with the THP GGAS patient education classes, while Dr. Surgeon desired to learn more about surgical outcomes. Ultimately, the guide encompassed four overarching sections: 1) Background and thoughts about considering surgery; 2) Reflecting on the surgical experience; 3) Thoughts on patient education classes; and 4) Feedback for the THP program and surgeons. Although the interview guide proved comprehensive, the way in which it was structured made the interviews less narrative, thus decreasing the nuance of responses during interviews.

The interview guide also changed as I progressed through interviews. I removed questions that seemed to fall flat, while adding others that enhanced meaning and understanding of the topic. A source for these new questions derived from one question that I asked at the end of each interview, where I asked each participant if there was a question that I should have asked during the interview. While the participants provided many interesting and insightful ideas, I only added two questions based upon feedback I 
received. These questions related to educational resources desired by people interested in GGAS, as well as a question relating to the concept of wanting to "give up" when in pursuit of GGAS. The question related to "giving up" especially resonated with participants in later interviews, resulting in one of the overarching themes discussed in this paper.

Prior to each interview, linformed participants that they had the ability to decide what questions they wanted to answer or skip, as well as inform me whether they would like to end the interview early. Overall, interviews lasted anywhere from a half hour to an hour and a half. At the start of each interview, I encouraged participants to talk openly, share theirfeelings, and emphasized that we were in a safe space to share information. My goal was to ensure I created a space where participants felt they would be represented with respect and dignity in relation to their gender identity, in addition to their other identities (Ferguson, 2013). I guaranteed each participant their confidentiality, making clear that I was working not as an employee of the THP, but in partnership with the program. As such, anything shared between the participant and I would remain confidential.

Following interviews, I submitted audio files for transcribing to either one of two transcription services: Temi.com or Rev.com. I took time to review each transcript for accuracy in content and grammar prior to sending them out to participants for their review and approval. Upon sending transcripts, I informed participants they had the choice to either omit or add to sections of their transcript, ensuring them that I would 
use their approved version during analysis. This ensured that participants had control over the nature of content shared with me, as well as provided them with an opportunity to elaborate on specific points throughout the discussion. Once I received all approved transcripts, I initiated qualitative data analysis.

As a first step, I conducted an initial reading of transcripts to comprehend the data in its entirety. Having the opportunity to review the transcripts without codes enabled me to identify emergent themes without losing connections between the concepts and their context (Bradley et al., 2007). After reviewing all transcripts, I imported the Word files into the NVivo 11 software program (QSR International, 2015). I then expanded upon the initial list of themes and developed codes using an integrated approach to developing code structure. Deductive codes derived from the framework of the interview guide (e.g., unexpected surgical outcomes, topics suggested for class curriculum). Inductive codes emerged from a line-by-line analysis of the text, where I constantly compared text segments to previously coded segments to ensure accuracy in coding (Bradley et al., 2007).

\section{My positionality and practices of self-reflexivity}

It would be remiss of me to not address my own positionality, especially with regard to data analysis. Despite the fact that I did not always share a common identity with participants, I was and continue to be cognizant of the influence of my own subjectivity on the research process and modes of knowledge production (Vargas, 
2008). Although I tried to create an environment where power is mutually shared between participant and researcher, the fact remains that a powerimbalance between the two is near inevitable. Ultimately, I have the final call in choosing what is represented in the results presented to the THP and Dr. Surgeon. Further, my own identity as a non-binary person who has not considered GAS places me at a disadvantage when interpreting the results, as I cannot feasibly understand the complex, and sometimes devastating, experiences of accessing gender-affirming care. To help mitigate the effects of these shortcomings, I consistently engaged in practices of self-reflexivity to avoid problematic representations that would perpetuate the alienation of queer subjects (Ferguson, 2013). Following each interview, I took time to review my notes, evaluating potentially biased assumptions. I did the same when developing the coding structure during qualitative analysis. I prompted myself with selfevaluative questions, such as "How do my positions of privilege and marginalization affect how I interact with, identify with and understand these lived experiences?" "Am I prioritizing some aspects of my identity over others during these interactions? If so, what are they and how is this affecting the data?" And finally, "How has my presence imprinted upon the data that I have collected?"

Inevitably, my position as a researcher and a representation of OHSU affected the manner in which I interacted with participants, with some participants approaching the interview from a formalized perspective. However, there were moments in which my other identities, particularly my racialized/ethic and genderidentities, 
overshadowed others. I found that I connected more with female Latinx participants, where we bonded over our mutual experiences as people of color living in a predominantly white Oregon. Undoubtedly, these differential interactions with participants are reflected in the responses shared with me. From an ethical standpoint, I acknowledge the varied intimacy shared with participants; yet I do not view these as obstacles to understanding. Instead, in the manner of Jessica Fields, I view these interactions as a means to recognize the assertion of personhood, where these interactions are a reflection of a more complex socialized existence that extends beyond the confines of the research space (Fields, 2016). As a final step in my self-reflective practices, I would engage in discussion with a sociologist/fellow researcher to process these concerns and figure out effective ways to address them. I found these practices to be incredibly helpful in addressing potentially problematic representations of participants, as well as highlight my own subjectivities as I navigated through the project.

\section{Phase 3: Integrate analytical findings}

After concluding data analysis for Phases 1 and 2, I integrated my findings using a methodological triangulation approach to identify "meta-themes" that appeared throughout the various data sources (O'Cathain et al., 2010). This involved a multi-step approach, as adapted from Farmer et al. (Figure 1) (Farmer et al., 2006). Following analysis, I drafted a final report for the THP and Dr. Surgeon. The 
report examines each overarching section in depth: 1) Background and thoughts about considering surgery; 2) Reflecting on the surgical experience; 3) Thoughts on patient education classes; and 4) Feedback for the THP program and surgeons. Further, the report highlighted recurrent themes that did not necessarily originate from the guide, but were recurrent throughout interviews. This provided for additional consideration for both the THP program and Dr. Surgeon, especially with regard to program improvement and topics for future research endeavors.

Soon after sharing the final report, I scheduled meeting times separately with the THP Program Administratorand Dr. Surgeon. During these meetings, we reviewed the results in depth. I also addressed questions either the Program Administrator or Dr. Surgeon had about the results or research process itself. Both provided feedback and edits on the report, specifically with regard to reporting structure and providing more clarity in some sections. I incorporated these edits and sent them an updated report shortly thereafter.

Phase 4: Develop curriculum recommendations and results dissemination

Following my initial meetings with the THP Program Administrator and Dr. Surgeon, we scheduled a larger meeting between the three of us to discuss our approach toward sharing results with the THP community. The THP community is comprised of the THP Advisory Board, OHSU surgeons, as well as community members interested in supporting or learning about TGNC health care. During this meeting, we 
reviewed the project findings, identifying themes and other salient messages from the data that would be useful in developing curriculum recommendations. The findings we chose to share with THP community members focuses on experiences in accessing gender-affirming care, opportunities to improve the GGAS curriculums, experiences with the surgical process and other surgical outcomes, advice for prospective GGAS patients, among other topics. We will also share our recommendations and plans to update the GGAS curriculums. We will present findings during an upcoming THP Community Meeting, scheduled for early May 2021. Following the presentation, THP community members will have the opportunity to provide their feedback and thoughts about the findings. We will leverage community member feedback to further refine curriculum recommendations, ensuring they reflect the expressed needs, priorities, and ideals of the THP community. Once recommendations are finalized, the THP will entirely take over the project's next and final steps. This involves updating the online curriculums that are currently in development, incorporating findings and recommendations deriving from this project. 


\section{Results and Analysis}

Acquiring health care coverage does not guarantee access to gender-affirming care

For many of the participants that I interviewed, accessing and establishing gender-affirming health care proved to be a barrier at times. Although insurance companies and government programs are beginning to provide coverage for genderaffirming care, the fact is that accessing such care remains inaccessible or difficult for many people. Once participants made the decision to pursue GGAS, they found several obstacles along the way - the most prominent being the dearth of providers who provide gender-affirming care. For some, this was a matter of living in a geographic location where providers of gender-affirming care were not available. Participants living in rural locations or in states where TGNC health care was not as advanced attested to this fact. Other participants lived in urban locations where care was accessible, but encountered resistant providers during their pursuit of accessing gender-affirming care. This discordance between the accessibility of medical coverage and the inaccessibility of gender-affirming care was frustrating for many of the participants I spoke with. Other barriers to accessing gender-affirming care discussed by participants included provider ignorance regarding the specific health care needs of TGNC patients. Monica, who completed vaginoplasty, spoke to the psychological issues that play into this dynamic. She viewed these obstacles to accessing gender-affirming care as an added stress to an already stressful life event, where she does not have control over the situation. In the following passage, Monica describes how she navigated the process of 
obtaining electrolysis services, which is a requirement for vaginoplasty surgery:

When I eventually did get all the letters in place it really became a matter of finding providers - like electrolysis was like a big issue. Trying to find somebody within the area that was willing to take it, not only the insurance, but take on transgender hair removal...But again, it was the obstacle of finding a provider and the associated mental stress with getting these things done. You want to look to blame somebody and you really want to blame the insurance company. It's just like, "Oh, you guys don't want to do this." And it really wasn't the case, you know?

What Monica, and many of the other participants who shared similar stories, are experiencing is the disjunction between progress being made in providing medical coverage for gender-affirming care and the inability of resources to keep up with this new demand. Whether or not this predicament is due to the limited amount of providers who provide gender-affirming care, the fact remains that health insurance coverage does not guarantee access to gender-affirming care. This issue is one that is often overlooked in broad discourse about TGNC health care, where the concern is primarily focused upon ensuring health care coverage for TGNC patients. Providing medical coverage for gender-affirming care is monumental progress; however, this accomplishment alone does not entirely solve issues of gender dysphoria and long-term health care needs for TGNC patients. Many TGNC patient navigating the health care system find the frustration of accessing basic health care as aggregating feelings of dysphoria, among other mental and emotional comorbidities. Accessing genderaffirming care is an ongoing learning process for many TGNC patients. In her own way, 
Monica, among other TGNC patients, has learned how to effectively navigate the system and access care. Yet accessing basic care should not be this difficult.

\section{Wanting to "quit" pursuing gender-affirming care/surgery}

When discussing their experience in accessing GGAS, many participants alluded to the idea of wanting to "give up" their pursuit at some point during the process. There were numerous reasons participants listed as to how they arrived at this decision. Issues with providers were among the top reasons mentioned by participants. The decision to undergo GGAS is significant for many TGNC patients, and many patients are understandably very excited to have the opportunity to finally occupy a body that is in alignment with their gender identity. As such, many patients pursuing GGAS have their own set of expectations with regard to functionality and aesthetics, feeling that their new anatomy is another step toward affirming their genderidentity. Feelings of frustration or disappointment were common among patients who had providers whom they felt eitherfailed to take their expectations into consideration, or were unsuccessful in effectively communicating realistic surgical outcomes.

Another participant I spoke with described feeling frustrated at two distinct points prior to completing GGAS. In preparation for phalloplasty, Joseph received hormone therapy, which is an initial step in the surgical trajectory of GGAS. Joseph discussed how his hormone therapy did not take initially, meaning the results he expected were not visually manifesting. Later, Joseph experienced complications with 
his top surgery, specifically during the recovery period. This complication affected the aesthetic appearance of Joseph's chest, which was not an outcome that he expected, rather less told about, when considering top surgery. Both events caused Joseph to experience feelings of frustration, making him question whether or not it was worth pursuing GGAS:

I kind of hit that wall early on. When I was taking my hormones, my testosterone levels were just not getting to where they should be. I still have that problem sometimes...the testosterone is not staying in my system like it should be. There's been a lot of times where, because that is such a big part of transition and is, you know, living as a male. There have definitely been times where I'm just like, "What's the point? If the hormones aren't going to stay in my system and if it's not working, why am I going through all of this?"

In this passage, Joseph associates the success of these medical interventions with the expectations of living in accordance with one's gender identity. Joseph's experience reflects that of many other participants that I spoke with, who felt a sense of dysphoria in addition to disappointment when their results did not match their expectations nor desires. Many participants placed the onus of responsibility on providers, in whom they placed a significant amount of trust for carrying out their vision. Some patients believe it is the responsibility of the provider to be attentive to their needs and expectations; when making the decision to undergo GGAS, patients are placing control in the hands of the provider. This intimate arrangement between provider and patient encompasses an element of trust. If this trust is broken, patients may not only feel disappointed in the outcome, but may also feel regretful or not in 
control of their own fate. This especially resonates with TGNC patients, who sometimes seek gender-affirming care to address feelings of gender dysphoria. Complications associated with gender-affirming care may enhance these feelings, causing the patient to question the value of continuing their pursuit of GGAS. Fortunately, many participants that I spoke with had adopted coping mechanisms to move past this hurdle.

Support systems, particularly those comprised of family and friends, were integral for many participants when attempting to move past the instinct to "quit". Participants, such as Case, had people in their lives who reminded them to stay focused on their ultimate purpose for choosing to have GGAS. Case, who considered quitting between surgical stages, had his girlfriend to thank for helping him complete the final stage for phalloplasty:

To be honest, I'm the kind of person that - I don't know if it's with my autism. I don't know if it's because I have past trauma. I don't know if it's cause I have extreme anxiety, but like when something overwhelming happens, my first thing is to give up. Just quit, give up. Don't even deal with it. Just pretend it doesn't exist. And my girl, thankfully, my girlfriend is wonderful and she continues pushing me. She's like, "It's okay. It's going to be okay." There have been a couple of times during surgeries that I just wanted to quit. I almost didn't get stage three and because I had - so me and [Surgeon] had a falling out. He was straight just being disrespectful and treating me like shit, and I wasn't gonna take it. And I was like, "No, I'm done. I'm not getting stage three. I'm not going up there. I'm not going to see him anymore." And had my girlfriend not calmed me down and was like, "I know this sucks, but let's just go. Push through." And then I tried walking out in the appointment and my girlfriend again was like, "Just, just sit down and breathe." Had it not been for her, I would have given up a couple times during these surgeries. 
Other participants mentioned additional coping mechanisms for moving past this obstacle. Self-motivation was key for some participants, while others said the thought of living with gender dysphoria the remainder of their life helped them move forward.

Conversations regarding the pursuit of GGAS do not often involve discussion around the concept of "quitting." However, this experience appears to be shared by many people who have been through the process of accessing GGAS. Normalizing such discourse would likely aid others who are navigating through similar experiences, and lessen the obscurity of this topic. Patients who have successfully or unsuccessfully moved past this obstacle have meaningful insight into this experience, which would be profoundly helpful to other prospective GGAS patients, as well as providers of genderaffirming care.

\section{Supportgroups}

Once a decision is made to undergo GGAS, many individuals find themselves faced with the immense task of piecing togetherinformation about the surgery. With various sources of information available online and through institutions, such as OHSU, it can become difficult to discern what information is and is not relevant and valuable. As part of the interview guide, I asked participants their thoughts about the prospect of the THP forming a support group that would be an extension of the existing GGAS patient education classes. A majority of participants favored the prospect of forming a 
support group, noting the group's potential to serve as a resource for information for those who may desire more in-depth information about a specific surgery.

Aside from serving as a resource of surgical information, participants saw support groups as an opportunity to learn from patients who have completed GGAS. Patients offer invaluable insight into the surgical process, as they are able to speak from a position of personal experience. Many of the participants that I spoke with desired to know what to realistically expect from surgery, especially with regard to post-op recovery and complications. Although surgeons are knowledgeable from a provider perspective, they simply cannot convey the experience of undergoing GGAS. As Case points out, providers may not always be the most valuable resource for patients:

To be honest, I'm a firm believer that you don't understand what I'm going through unless you've gone through it. So I'm going to go directly to the source. I mean, I know the surgeons "owns" or did it, but he doesn't always know about recovery in my opinion.

Support groups were also seen as a safe space for prospective GGAS patients to ask questions; specifically, questions that they do not necessarily want to ask their provider. This may be due to eitherpersonal reasons (e.g., comfort with provider), the limited availability to access providers, or because prior GGAS patients can better speak to these experiences. Likewise, support groups were viewed as an opportunity to provide a space for those who may not know or have other people with whom they could discuss their interest in GGAS. As such, support groups were regarded as a 
valuable resource for people who are interested in GGAS, but for various reasons do not have the means do not have the ability to have conversations about their decision.

The experience of undergoing GGAS is multi-faceted in that encompasses many transitions that extend much farther than the physical. GAS is especially unique and complex in that it incorporates transformations related to social location and identity formation. Although many TGNC patients live according to their genderidentity prior to surgery, surgery itself significantly alters the way in which the body navigates through the world. This drastic shift has meaningful and lasting implications, which requires an ongoing learning process. As such, having connection to others who have or will go through the same experience can be insightful for some prospective patients. This can be especially true for TGNC patients, many of whom deal with the threat of transphobia and related mental strain throughout their lives. Whether due to the threat of violence or the lack of social support, many TGNC patients would benefit by having a space to process these traumas, as well as connect with others.

For some participants, support groups were seen as social spaces and safe havens for TGNC patients. Establishing social connections with fellow TGNC individuals may be difficult for some, especially for those who live in remote areas. Having access to peer connection and support, whether online or in-person, was seen as a benefit for individuals who may be experiencing mental strain as a result of pursuing GGAS or due to other traumas experienced as someone who is TGNC. For Monica, human interaction was imperative for addressing mental strain experienced by TGNC individuals: 
Humans need that human to human interaction. Especially if you're in a fragile state, and a lot of transgender people are. They've been pushed to their limits, like mental limits and physical limits for the time that they've waited, either by their own procrastination or by obstacles along the way. And anything you can do to lessen the mental strain I think would be good.

Many participants agreed that having a support group serve as an extension of the existing GGAS patient education classes would be an added benefit for people at any stage of GGAS. However, not all participants felt that OHSU would be the appropriate host for such a group. In particular, there was concern over whether these spaces could truly be "safe" if the institution is looming in the background. Jordan, who completed phalloplasty, felt it would be difficult to openly critique the institution in a space moderated by said institution. Reflecting on his own negative experiences with a surgeon, Jordan expressed concerns over potential retaliation or censorship if attempting to critique the institution or his surgeon:

I think I do have a good amount of distrust for those types of spaces being created within the institutions that are offering care. I think it doesn't allow for the independence and the ability to critique those institutions if they're housed under them. Because if you critique them, then whether or not there are policies in place to prevent like retaliation for somebody for, you know... Like that's not the place that you're going to feel comfortable talking about the problems that you had. I don't think there's really any way to work around that reality. I think it's better when the spaces are independent, but I also understand that there's a real value to having some in-person or more hyper-specific support...So I don't know. I don't particularly like the idea of having those sorts of spaces run by the people who are providing care. 
In his reflection, Jordan brings up an interesting point related to centering services under one institution. Is OHSU the appropriate venue for hosting support groups for TGNC patients? Or would patients be better served by an independently-run support group? Is it feasible that such censorship would carry over to peer support groups?

With this in mind, there are several points to consider with regard to forming a patient support group for GGAS. Can groups function openly and without fear of retaliation if hosted by an institution? For groups hosted by an institution, whose needs are prioritized (e.g., the patient's or the institution's)? And finally, what happens when these services are centralized under the umbrella of an institution? Regardless of approach, the power dynamic between patients and the institution are unequal when services such as support groups are institution-led. Under this dynamic, patients may feel a sense of disempowerment, replicating the experience of powerlessness that they may encounter in their daily lives. To go even further, patients may perform to perceived expectations within these spaces, either physically or discursively controlling their performance. As such, these dynamics render the meaning of "safe space" void, as patients may in fact not feel safe enough to openly express themselves in such spaces. However, this may not be an issue for others, who may have more trust in the institution and thus would support an institution-hosted peer support group.

\section{$\underline{\text { Patients educating patients }}$}


Lived experience is a valuable tool in educating others, especially when it comes to educating prospective patients about what to expect from surgery. Not only can it be a daunting task for patients to navigate through the morass of information available, the process of deciding the applicability of these accounts can be likewise overwhelming for some. For many participants that I spoke with, learning from other patients was valuable in not only assembling information, but as a decision-making aid for GGAS. Beyond the decision to undergo GGAS, patients must consider their many surgical options, as well as the short- and long-term implications for surgery. Sometimes these implications, such as post-surgical complications, are not discussed or simply overlooked during patient-provider interactions. For example, a few participants I spoke with did not anticipate permanently losing sensation in their hand after phalloplasty surgery, which requires harvesting a skin graft from their forearm. Having the ability to learn from prior patients would have better prepared these patients for such unexpected outcomes. This oversight may be due to several reasons: the fact that providers do not want to worry patients ahead of their surgery, the desire for professional selfpreservation, or because the provider simply does not regard this topic as important. Whatever the reason, having the provider or THP in control of what is communicated to patients is problematic in that they decide what is most important for patients to know, as well as perpetuates an authoritative-style learning format that may not resonate with patients interested in learning more about GGAS. 
Another byproduct of navigating through information, especially online, is the prospect of coming across unfavorable surgeon reviews or personal narratives regarding GGAS. For some participants, this negative information either made them question their decision to undergo GGAS or to be fearful that they would inevitably experience these same outcomes. Having the opportunity to hear from other patients who have completed surgery, especially under the same surgeon, put fears at ease for some while also facilitating a more positive outlook on the decision to have GGAS. For Jamie, who completed vaginoplasty, finding negative reviews online made herinitially feel uneasy about the surgery. However, reading the narratives of other patients of the same surgeon helped reframe her expectations:

I had made the mistake of going and looking up surgical results, something you should never do for any form of surgery, I am now convinced. Some of them were horrendous. Some of them weren't great, but it's terrifying. And of course, reading people, random people on the internet and their experience doesn't necessarily equate to, okay. They were at a different doctor, a different facility with different skillsets. So happily in my case, I was able to find a site that actually had people who had surgery from him and was able to read there. So I would tend to agree that that is very important and very useful because you can actually read at least a few people. It's not, obviously not the hundreds that he's done, but the people who have commented on whether they were happy with the result, what they went through and everything else. So, it is very helpful.

Like Jamie, hearing patient narratives can help prospective patients manage their expectations with regard to surgery and related outcomes. Many participants said that patient narratives provided a broader perspective of the surgical trajectory, spanning from the actual surgery to long-term health care considerations. These narratives 
provide in-depth insight into the recovery process, addressing aspects of recovery and aftercare that are not part of the broader discourse of GGAS. Knowing what to expect in advance can help manage patient expectations, which in turn would likely improve postsurgical outcomes. Having the knowledge of what to expect during and after surgery, as well as during the recovery process is integral information for many patients considering GGAS. From the narratives I heard, the range of post-op complications that occurred were varied and caused an incredible amount of distress for patients. Most of these complications could have been easily prevented with knowledge on how to recognize these complications as they occur. Further, information on long-term aftercare and hygienic needs is sparse for individuals considering GGAS. Many of the participants that I spoke with, particularly those who completed eithervaginoplasty or vulvoplasty, did not consider the implications of having a completely new set of genitalia. Some patients are so focused on completing surgery that long-term needs are rarely taken into account when considering GGAS. Jamie described her experience in having to become acquainted with her new anatomy post-surgery:

Make sure that you have somebody who can help take care of you and hopefully have somebody around you who's female who can answer a lot of really stupid questions because there are some really simple nuances to things that you're not going to know and there aren't instructions. So for instance, cleaning yourself, taking a shower. I spent 40 years with doing it one way. What's the right way now? So yeah. It's simple things like that. That to anybody else seems like, "How could you not know that?" Well, because that wasn't a thing for me.

Being equipped with practical knowledge before undergoing GGAS can help mitigate the many frustrations GGAS patients may encounter post-surgery. Yet from 
discussions I had with participants, it seems such practical knowledge is being omitted from patient-provider interactions as well as within educational contexts. Providers may argue that patients may not seem interested in learning about these issues, or that their scope of work does not extend tolong-term maintenance. However, how could patients express interest on a topic in which they know nothing about? This is yet another reason why including patients who have completed GGAS as part of the knowledge sharing process is important. Not only do patients have the opportunity to learn from others who have been through similar experiences, but they likewise can envision what that experience would be like as they see a reflection of themselves in the patient educators.

Although most participants supported incorporating prior patients into the educational setting, some expressed unease over the prospect of the institution curating patient narratives. In other words, there was concern whetherinstitutions were selecting patients based upon their favorable outcomes. Jordan, who did not attend the THP patient education class, offered his own thoughts on incorporating patients into institution-led patient education classes:

So I didn't necessarily know what the class would be, but would personally say that in the context of a class that wouldn't be super helpful to me because they're going to be cherry-picked, like positive representations. I'm sure if you've done any amount of research into this subject at all, like you've somewhat at least become aware of the massive problem of like really unethical, predatory surgeons in the country. Like, I would probably say it's about a 40 to $60 \%$ split of people being like egregiously bad. 
Jordan's statement is reflective of other similar statements I heard concerning the integrity of information presented by the institution. This calls into question whether or not the institution and THP are complicit in constructing an idealized GGAS patient with favorable post-surgical outcomes. This argument can be viewed from two perspectives. First, it is understandable that the THP would want to present the bestcase scenario - for the program's reputation, as well as retain prospective patients and not distract them with probable outcomes. Yet not being completely transparent in communicating unfavorable outcomes, such as those related to post-op complications, is itself a dilemma that the THP must contend with.

Jordan's thoughts left me with questions to consider regarding the implications of curating patient perspectives, especially within the educational setting. What is the cost of this curated presentation? What are the short- and long-term impacts of presenting the idealized GGAS patient? The most obvious impact, of course, would be related to post-surgical patient satisfaction and outcomes. For example, if a patient were to not achieve an idealized outcome, this could have an effect on their perception of personal satisfaction with their results. If dissatisfied, this could lead to feelings of dysphoria or regret. Further, patients may feel disempowered by failing to achieve the idealized outcome set forth by the institution and program. From the participants that I spoke with, complications often initially led to feelings of dissatisfaction. Yet when these participants learned from other patients that their experiences were actually quite common, this reframed the perception of their results. This issue can be easily mitigated 
with transparent conversation around surgical outcomes and related complications, as it would help prospective GGAS patients manage their expectations before deciding to proceed with surgery. Yet can transparent conversations happen within an institutionled educational setting? Or will the institution be more invested in preserving their image rather than have these frank discussions? These are thoughts for OHSU and the THP to consider when revising their GGAS patient education curriculums. 


\section{Discussion}

This project leverages a patient-centered approach toward educating prospective patients of GGAS. Through utilizing lived experience as the basis of knowledge production and distribution, prospective patients of GGAS have the opportunity to better prepare for the significant transitions (e.g., physically, mentally, socially, etc.) that occur in conjunction with surgery. Applying perspectives of Queer of Color Theory in educational settings, transformative practices, and discursive aggression revealed the unique challenges and needs that patients of GGAS encounter along the surgical trajectory. Evidence points to the fact that much improvement is to be made in the realm of TGNC health care, extending beyond the mere acquirement of medical insurance coverage. The primary contribution of this project is an enhanced understanding of how TGNC patients navigate the health care system when pursuing GGAS, as well as identifying the prioritized needs of these patients.

Establishing support group systems and centering patient voices within educational settings were the most important elements identified by this participant group. Due to numerous obstacles patients encounter while pursuing GGAS, many may feel discouraged and thus inclined to "quit" their pursuit. Though GGAS was the last step for many in affirming their genderidentity, these obstacles prevented some participants from completing surgery. Examples of obstacles encountered by participants included the limited number of gender-affirming providers, feelings of disappointment with medical outcomes, or lack of social support systems. For some, the 
onus of responsibility laid with the provider, who failed to manage expectations regarding post-surgical outcomes. Health care providers may have a specific conceptualization of what is necessary for patients to know when considering GGAS. These priorities may differ drastically for patients, who must not only deal with the reality of recovery but must likewise adopt new long-term aftercare practices as well as becoming acquainted with a new body. Not being adequately prepared for life postsurgery led to feelings of disappointment for some participants, who had not previously considered the long-term implications for their decision. Providers, wholikely have not completed GGAS, simply cannot speak to the lived experience of undergoing GGAS. This is one reason as to why patient perspectives are important in health care education.

The purpose of this project was not only to understand the experiences and priorities of patients considering GGAS, but to develop curriculum recommendations based upon this information. There are more recommendations for the THP that are beyond the scope of this paper, all of which are still under review by the program. However, two primary recommendations derive from the themes presented here. First, the THP should consider facilitating a patient support group in some form. If hosted by the institution, the support group would act as an extension of the GGAS patient education classes and be comprised of individuals at any stage of considering GGAS. The benefits of support groups are many, but mainly address two primary needs - patient representation within the educational context, as well as establishing a support system for patients who may desire one. As participants noted, patients who have been 
through the surgical process are an invaluable resource when it comes to educating prospective patients. The experience of undergoing GGAS is unique in that it encompasses many transitions that extend beyond the physical, especially with regard to social location and identity formation. Further, GGAS is an invasive surgery that has long-term implications, many of which providers may think unimportant to consider. Support groups are a means to communicate information that may not be readily available, or ideas that patients had not considered before. With more information on hand, patients can better manage their expectations regarding post-surgical outcomes, thus likely increasing preparation, feelings of empowerment, and perception of satisfaction regarding results. For patients who lack social support systems, these groups can serve as a mechanism to help them overcome obstacles or connect with resources as they pursue GGAS. However, the question remains whether OHSU and the THP should host the support group. Concerns over establishing a safe space for patients and fear of retaliation are valid arguments to consider, all of which must be considered by the program.

The second recommendation relates to incorporating prior patients into knowledge production and educational settings. Learning from lived experience is a means to understand how external forces shape marginality, as well as provide insight to the needs and priorities of marginalized communities. Traditionally, most educational teaching models have taken a hegemonic approach, relying upon a "banking system" of learning where learners are not part of the knowledge production and sharing but are 
expected to serve as passive subjects during the learning process. This has typically been the structure of the GGAS patient education classes hosted by the THP, where educational curriculums are devised by the surgeons and program administrator. Patient perspectives have not been prioritized in these settings, making for a one-way dialogue that does not address the nuanced needs of GGAS patients. This arrangement thus establishes a hierarchy where knowledge production is reserved for one group (i.e., the institution), thus concentrating its power and authority over patients. Participants that I spoke with desired to see more patient representation in educational settings, as they felt prior patients offered valuable insight into the reality of completing GGAS. Patient representation in educational curriculums can also be a form of empowerment for other patients, who see a physical representation that it is possible and worth completing surgery. Incorporating the lived experiences of patients into the curriculums would not only make for material that is highly relevant for prospective GGAS patients, but would also serve to destabilize the power imbalance between the institution and patients. In turn, marginalized identities are affirmed through the politics of representation and visibility. However, who represents patients and the manner in which patients are represented is still a matter of concern. If the institution and program have the power to choose patient representatives, the power imbalance remains. Further, these actions may further perpetuate the medical construction of the idealized TGNC patient, which itself has long-term negative implications for other patients completing surgery. These are issues that the program must meaningfully 
consider and address when updating their curriculums.

This project is limited to one institution in a concentrated geographic location. The uniqueness of the THP offers an opportunity to gain insight into patient experiences of acquiring GGAS, as well as the process of knowledge production for patient education classes. Future research should examine the experiences of GGAS patients in rural areas and in locations where programs such as the THP are not readily accessible. Such projects would provide greater understanding into the diversity of priorities and needs among TGNC patients across a wider geographic range. Additionally, having more comprehensive data would hopefully lead to additional educational resources and programs for individuals considering GGAS. This in turn would lead to betterinformed decisions regarding GGAS, as well as improved preparedness and post-surgical outcomes for patients.

If institutions are to serve as the primary mechanism for patient education, then they must incorporate practices that better serve their communities. This is especially true for TGNC patients, who encounter numerous obstacles in their pursuit of genderaffirming care. When institutions, such as OHSU and the THP, take care to support and affirm TGNC patients, patients are more likely to feel empowered and make informed decisions about surgery. Therefore, when developing resources for prospective GGAS patients, OHSU and the THP must take care to incorporate patient needs and perspectives into educational materials and resources. Patients likewise need to be part of the knowledge sharing process, educating other prospective GGAS patients. There is 
much room for improvement in how OHSU and the THP educate GGAS patients;

enacting these recommendations are a step in the right direction. 


\section{Significance of Research}

This research project adds to the dearth of literature examining the needs and priorities of patients who are at any stage of considering GGAS. The one study examining the effectiveness of patient education classes for gender-affirming surgery limited their analysis to measuring patient satisfaction with perceptions of preparedness and post-surgical satisfaction. This study goes in-depth to examine the surgical trajectory in its entirety, spanning from the decision to have GGAS to completing surgery. As such, additional insight is gained into the barriers encountered by prospective GGAS patients, as well as patient-identified resources to help mitigate the effects of these obstacles. Incorporating patients into the knowledge production process is an approach that is not commonly utilized within health care patient education settings. This project offers substantial evidence that, for marginalized communities especially, it is imperative to ensure patients are reflected and incorporated into educational settings in order to create content and resources that are highly relevant, meaningful, and affirming to prospective patients of GGAS. 


\section{Reflection}

When beginning this project, I went in with the mentality that I had been through the gamut of experiences with regard to research - ranging from the absolute worst to best case scenarios. Never did I imagine that this project would serve as a sort of "coming of age" for me, both personally and professionally. Formany reasons, I am not the same person that I was this time last year. That is a very good thing. I could likely pen an incre dibly self-indulgent novella about my transformative experiences with this project, but I will address some of the most significant experiences in the following pages.

\section{So, what happened to your theories?}

Although I was cognizant that engaging in a partnership would likely affect the scope of the research project, I did not expect it to change in the manner that it did. Call it naiveté, but my ideal project would have been a community-based partnership where I would uncover these truly incre dible and meaningful insights that flawlessly supported the theories I proposed. Now reflecting on this, I see that my mindset prioritized my own needs over that of the stakeholders. Thankfully, the project did not pan out according to plan as the THP (and others) were given an equal say in the research design.

So, some may notice that the results I acquired do not seamlessly conform to the theories I put forth in my initial proposal. What changed between then and now was the 
fact that I needed to address the information needs of the THP. Although I created the initial draft of the interview guide, I did not have entire control over the final version. The THP Program Administrator and Dr. Surgeon (to be discussed later), reviewed the guide and added questions of their own while removing some of mine. Both had their own interests at stake in this project. For the Program Administrator, they wanted substantial feedback about the effectiveness of the GGAS classes; Dr. Surgeon wanted to learn more about surgical outcomes for GGAS patients. As such, my semi-structured guide became incredibly structured, which meant that responses were going to be less narrative. It likewise meant that I ran the risk of having exhaustive and long interviews, much longer than the hour I had anticipated. I did work on the guide further to pare down the amount of questions, but still ended up with a lengthy guide.

Reflecting on this experience now, I may have approached this scenario slightly differently. Perhaps I would have pushed for a more semi-structured guide to allow for rich data collection. However, there is compromise in these research partnerships. To me, it was more important to prioritize the needs of the program as opposed to that of my master's project. In all, it still worked out as some of the questions I included in the guide resulted in interesting narratives that took the research in unexpected directions. Some of the themes presented here derive from those very questions.

\section{A new stakeholder in the game}

As noted in the methods section, I engaged in a new partnership with a 
stakeholder just as I was about to begin Phase 2. During one of our routine check-ins, the THP Program Administratorinvited Dr. Surgeon in order to introduce us to one another. Dr. Surgeon is likewise engaged in TGNC health research, and has many projects currently underway. By the end of the meeting, I found myself walking away with a new stakeholder to whom I must also report. At the time, I did not consider the implications of engaging a new stakeholder. I was more so ecstatic about the fact that I did not have to worry about self-funding the gift cards for the interviews.

It was not until we were in-process of refining the interview guide where I began to witness some of the control I had lost in this new partnership. As a stakeholder with a vested (financial) interest in the project, Dr. Surgeon had as much say about the research design and interview guide as me and the THP Program Administrator. There are two sides to this new arrangement, good and not-so-great. The positive outcome was that Dr. Surgeon incorporated questions into the interview guide that would later serve as excellent prompts for participants. These questions broadened the interviews in a manner that was beyond my ability at the time, and for that I am grateful. Additionally, Dr. Surgeon provided me with a contact list of her patients, which I was allowed to utilize for Phase 2 recruitment. I am without doubt that having access to these resources supported the project's success in a manner that I would not have been able to do on my own. Finally, Dr. Surgeon invited me to serve as a small group moderator for a summit they held in March 2021. This summit was an opportunity for research/TGNC communities to come together to learn about research, as well as form 
research questions for future studies focusing on TGNC health care. It was an incredible opportunity that I would never have fathomed to be part of, especially as someone who is still so "young" in their chosen field of research. I cannot express enough gratitude at the opportunities this partnership has provided me, despite the limitations I experienced at some points during its trajectory.

For me, the positives of this new partnership far outweigh the "negatives". One significant negative, or rather limitation, concerned the purchase of gift cards. Since the gift cards were not being purchased with my own funds, I had to cede my control of this aspect of my project to someone else. Dr. Surgeon had initially planned to purchase Visa gift cards through Amazon; however, every time they attempted to do so resulted in their account being flagged as fraud and immediately shut down. We decided to issue gift cards through OHSU, using its service with ClinCard. This meant that I had to work though Dr. Surgeon's financial administrator, who worked on her own timeline and had a different priority level for this request. Acquiring the gift cards meant a lot of waiting, follow-up emails, and submitting additional information as requested by the financial administrator. Although we had started working on the ClinCard request prior to the first interview, I did not acquire and thus was not able to send gift cards out to participants until a month and a half after the first interview. As such, I was placed in a precarious situation with participants as I was the "face" of the project. There was one participant in particular that was unhappy about the wait (understandably). Yet their upset also reminded me to be more diligent about communicating with the other 
participants about the situation at hand. After sharing an update, other participants seemed to understand and said they were fine waiting. I was lucky to have participants that had compassion for my situation, although they should never have been put in that position to begin with. If I ever find myself in a similar situation in the future, financially, it would be something that I would outright consider from the beginning.

\section{You never know how hard it is until you do it on your own}

I am not new to research. In fact, I have been working in research for -8 years now? During those 8 years, I have been through the gamut in terms of scenarios that I have dealt with. Yet it was not until I managed my own research project that I realized how much I took for granted the fact that I always worked in teams, which meant that I was only responsible for a piece of the research pie, so to speak. What I have learned from this experience is that managing your own research projects is hard work! You are simultaneously a principal investigator, administrator, and research assistant without any support whatsoever. I had never anticipated how many hours it would take me to schedule participants, while juggling my non-academic responsibilities such as a fulltime job.

Managing your own projects means that you will inevitably drop the ball at some point. This could either be due feeling overwhelmed by the amount of responsibilities you have, or because you simply did not know. This happened to me with regard to my IRB approval at OHSU. Since I planned to conduct all my interviews remotely, I decided to update my protocol to acquire consent electronically via REDCap. Although I had 
acquired IRB approval, I later learned that I had not uploaded my consent documents in the correct format for the OHSU REDCap team to move my project into production. This was mere ignorance on my part, yet the backlash and admonishment I received from the OHSU REDCap team made me even more painfully aware of said ignorance. After consulting with IRB experts in my department, I figured out I should apply for a waiver of consent - meaning that I would be able to bypass using REDCap for consenting as I would only acquire verbal consent. What adds to the complexity of this awkward predicament is that I work with the REDCap team in my official position at OHSU as well. I have been able to work past this, but I believe that this situation could not have been avoided - I just needed to experience it in order to learn from it.

Finally, no one told me about the potential mental and emotional strain I would experience during these interviews. In the span of a month, I completed all 22 interviews. I would not recommend this same approach to anyone hoping to maintain a sense of mental and emotional well being. What made this time especially difficult was the sometimes heaviness of these interviews. I will be upfront in that I cried at least twice during interviews. The stories that participants so openly shared with me were devastating, especially stories where participants considered suicide when they thought that they would not be able to access GGAS. My pain is in no way comparable to that of the people wholived through them, and I think what frustrated me even more was that I was not in a position to help these individuals. These were moments of raw vulnerability, for which I felt despicable at times for absorbing theirvulnerability 
without returning it in kind. I still do not know how to deal with this innerconflict. I feel like I could have done better to navigate these situations, but I simply do not know how. I work with sociologists who conduct research in similarly heavy topics (e.g., childhood cancer), who recommended that I have someone on hand with whom I could debrief with after interviews. Mind you, I received this advice after I had already completed the interviews. Luckily forme, I had my partner at home in whom I confided after the especially tough interviews. This helped me significantly.

"You're doing important work"

I cannot tell you the amount of times I have heard this exact phrase during this project. Even after hearing it so many times, it still makes me internally cringe. My main attestation to this phrase is that it makes me feel like an impostor - that this project is incredibly important and that perhaps I am (was not not) the right person to carry it out. I firmly believe in that we should prioritize having community members conduct research within their own communities. I am not someone who has considered GGAS at any point in their life, which automatically makes me feel like the problematic researcher we are all too familiar with. What is more, my resources are limited as a graduate student. When I hear that I am doing important work, it makes me think that I do not have enough resources at hand to make this a truly meaningful and profound project. I am highly aware of the lack of research in this area, which adds complexity to the situation. This project is literally contributing to a current gap in evidence. When I 
consider this reality, it can become overwhelming at times.

Hearing this phrase from participants was probably the worst. Many of the people that I spoke with recognized the importance of this project, and likely had high expectations as far as outcomes are concerned. First, hearing that I am doing "important" work on behalf of GGAS patients makes me feel strange - especially hearing it from participants. I feel ingratiated to participants for offering their time and stories; as such, I do not feel as if participants should be thanking me for this work, as they are the ones taking on the burden of creating knowledge. Second, I have absolutely no control over the final outcome of this project. At the conclusion of this project, I am merely offering recommendations as to how to update the GGAS curriculums and THP. It is up to the THP Program Administrator and the THP to decide what to do with these recommendations. What happens if the Program Administrator and the THP decide not to implement any of these recommendations? What is the meaning of this "important work" if it does not go anywhere?

I know well enough to be aware that this project is not about me, and that this phrase was said as a means of support. I know it is important work, but it does not negate the fact that I continue to feel conflicted about my role in this project. I want to do well by the participants, the THP, as well as the TGNC community at-large. There is so much work to be done with improving health care for TGNC patients, and I want to support that in any way that I can. I do not and will never regret doing this work. It was an exhilarating experience that transformed me in ways that I cannot explain here (or 
maybe ever). If given the opportunity, I would do it again - yet differently, of course. I hope that this work will help someone, or at least provide the foundation for future research in TGNC health care. 


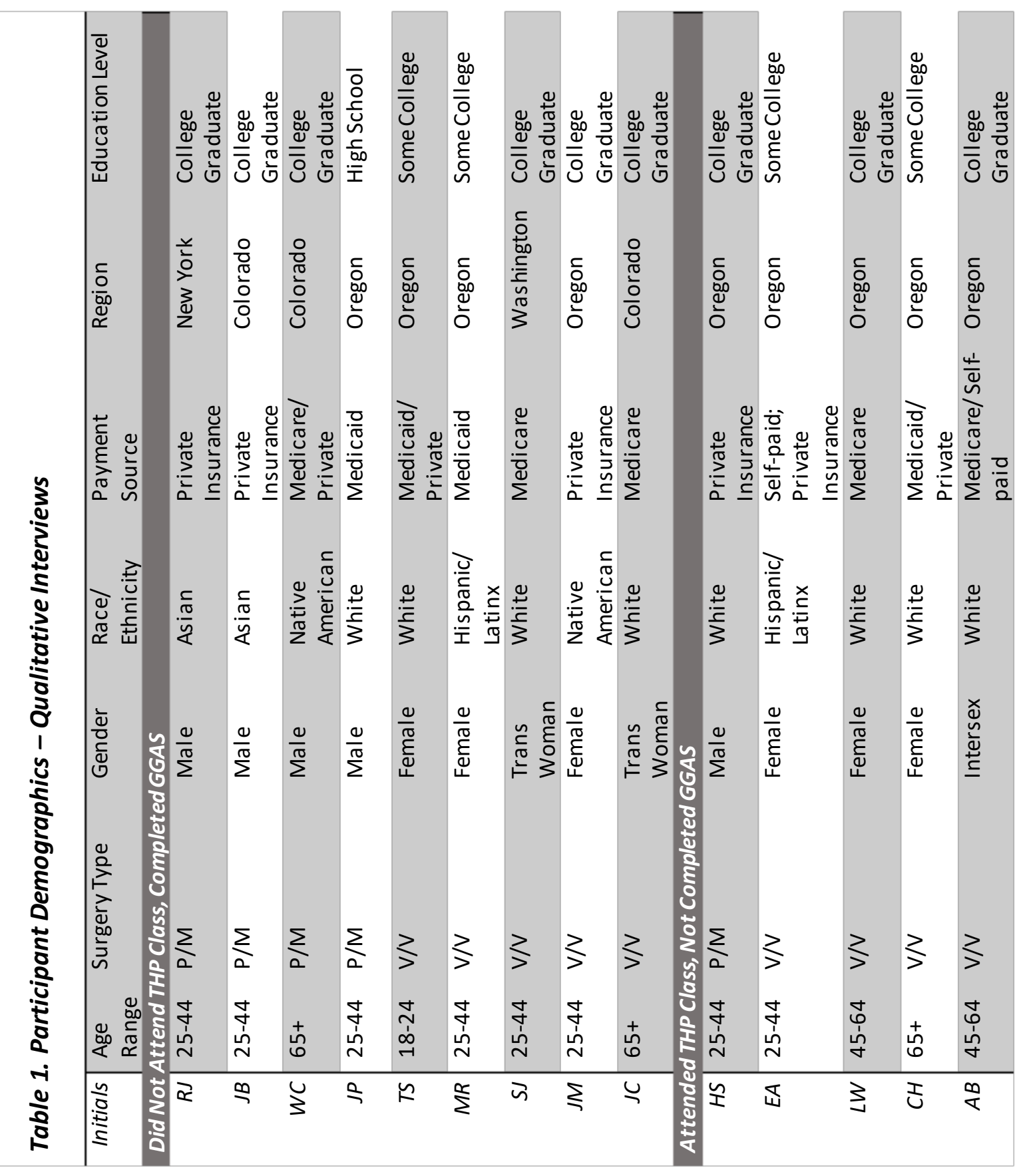




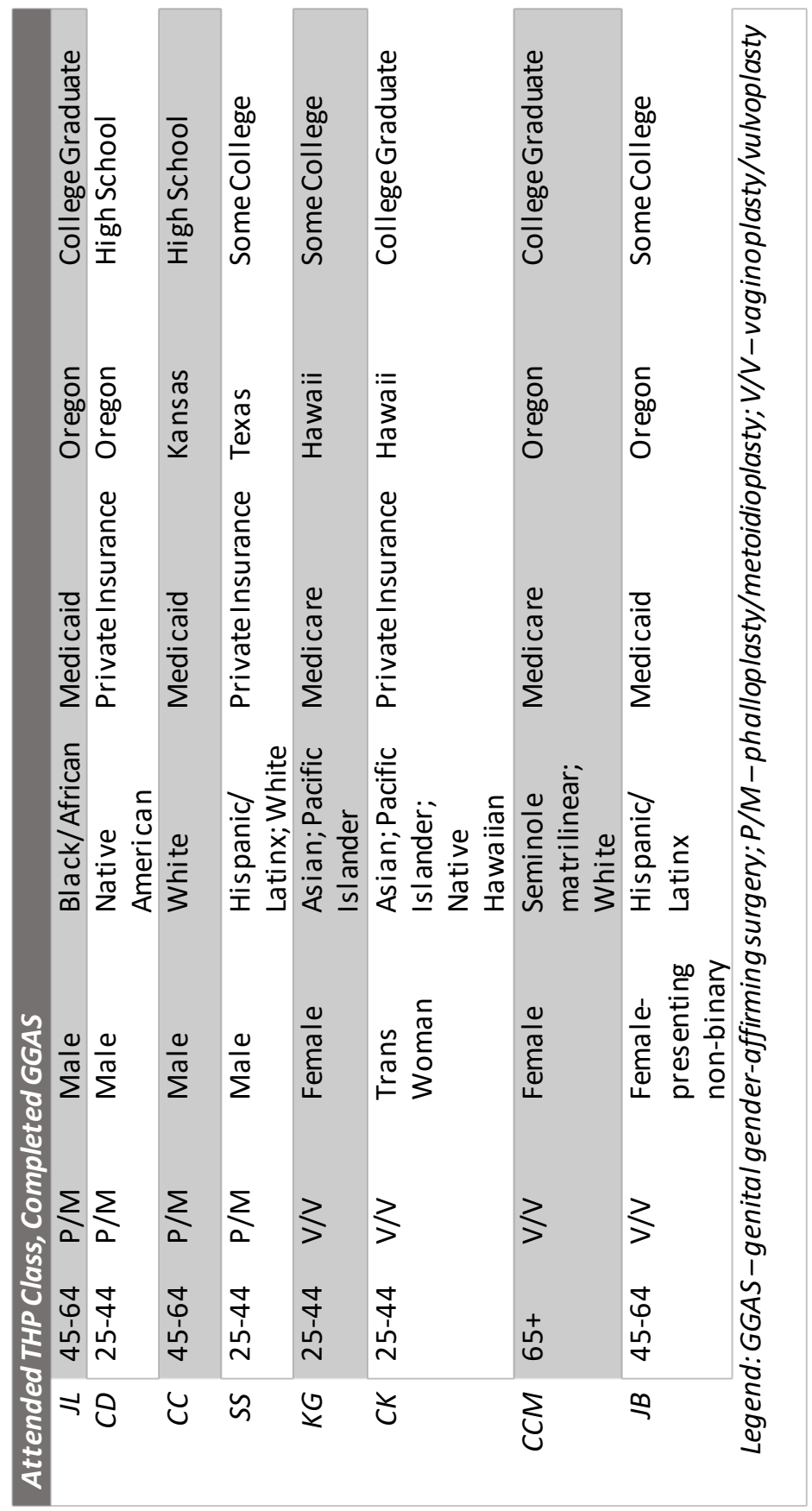




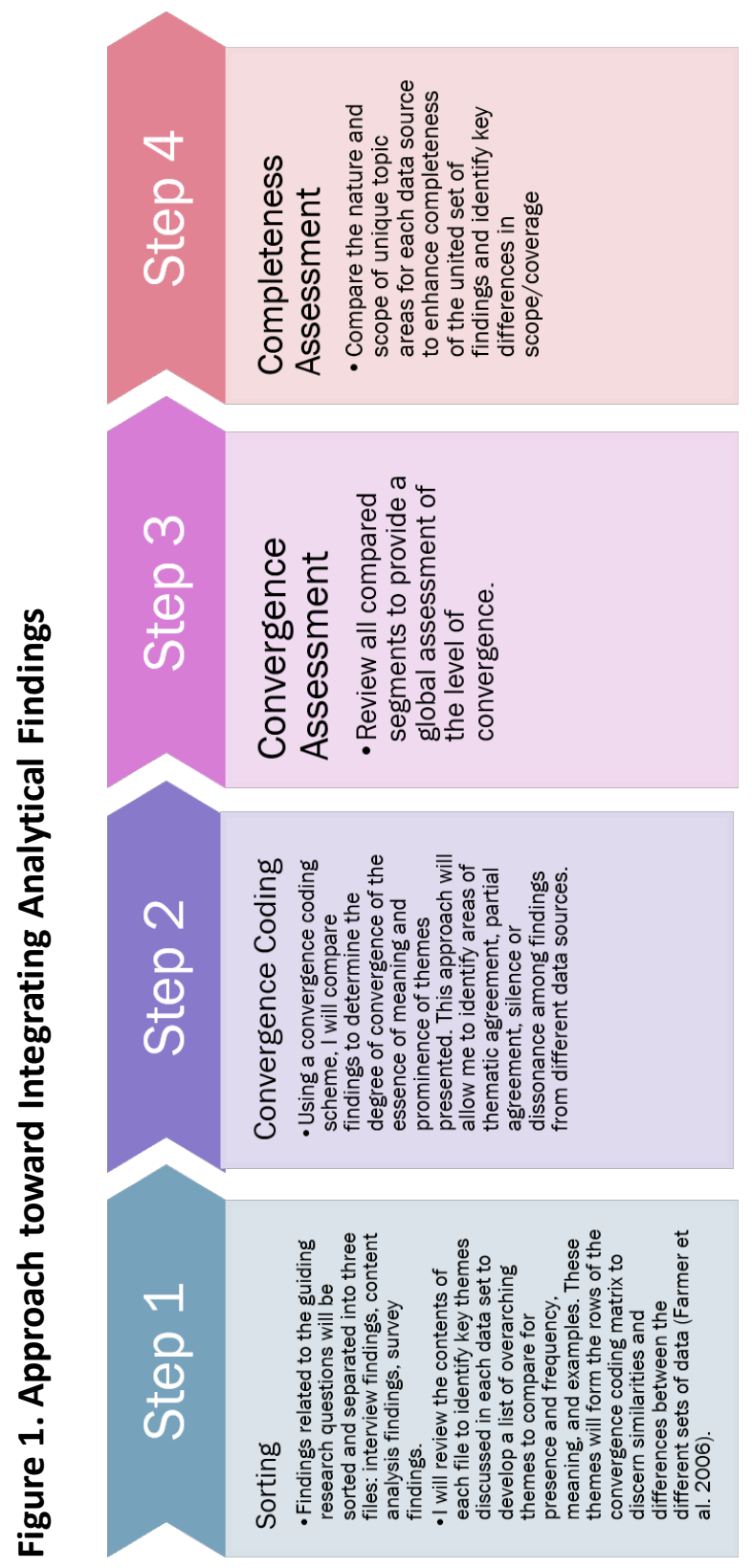




\section{References}

Baker, K., \& Beagan, B. (2014). Making Assumptions, Making Space: An Anthropological Critique of Cultural Competency and Its Relevance to Queer Patients. Medical Anthropology Quarterly, 28(4), 578-598.

Benotsch, E. G., Koester, S., Luckman, D., Martin, A. M., \& Cejka, A. (2011). Non-medical Use of Prescription Drugs and Sexual Risk Behavior in Young Adults. Addictive Behaviors, 36(1-2), 152-155.

Bradley, E. H., Curry, L. A., \& Devers, K. J. (2007). Qualitative Data Analysis for Health Services Research: Developing Taxonomy, Themes, and Theory. Health Research and Educational Trust, 42(4), 1758-1772.

Brockenbrough, E. (2015). Queer of Color Agency in Educational Contexts: Analytic Frameworks from a Queer of Color Critique. Educational Studies, 51(1), 28-44.

Brown, G. R., \& Jones, K. T. (2014). Racial Health Disparities in a Cohort of 5,135 Transgender Veterans. Journal of Racial and Ethnic Health Disparities, 1, 257266.

Butler, J. (1990). Gender Trouble: Feminism and the subversion of identity Routledge.

Canales, G. (2013). Transformative, Mixed Methods Checklist for Psychological Research with Mexican Americans. Journal of Mixed Methods Research, 7(1), 6-21.

Crosby, R. A., Salazar, L. F., \& Hill, B. J. (2016). Gender Affirmation and Resiliency Among Black Transgender Women With and Without HIV Infection Transgender Health, 1(1), 86-93.

Doan, P. L. (2016). To Count or Not to Count: Queering Measurement and the Transgender Community Women's Studies Quarterly 44(3 \& 4, Fall/Winter ), 89110.

Dragon, C. N., Guerino, P., Ewald, E., \& Laffan, A. M. (2017). Transgender Medicare Beneficiaries and Chronic Conditions: Exploring Fee-for-Service Claims Data. LGBT Health, 4(6), 404-411.

Farmer, T., Robinson, K., Elliott, S. J., \& Eyles, J. (2006). Developing and Implementing a Triangulation Protocol for Qualitative Health Research. Qualitative Health Research, 16(3), 377-394.

Ferguson, J. M. (2013). Queering Methodologies: Challenging Scientific Constraint in the Appreciation of Queer and Trans Subjects. The Qualitative Report, 18(13), 1-13. 
Ferguson, R. A. (2018, March 2018). Queer of Color Critique. Oxford University Press. Retrieved March 4, 2020 from https://oxfordre.com/literature/view/10.1093/acrefore/9780190201098.001.00 01/acrefore-9780190201098-e-33

Fields, J. (2016). The Racialized Fields of Participatory Research: A Queer Feminist Understanding. Women's Studies Quarterly, 44(3/4), 31-50.

Flores, A. R., Herman, J. L., Gates, G. J., \& Brown, T. N. T. (2016). How Many Adults Identify as Transgender in the United States? http://williamsinstitute.law.ucla.edu/wp-content/uploads/How-Many-AdultsIdentify-as-Transgender-in-the-United-States.pdf

Foucault, M. (1980). Power/Knowledge: Selected Interviews and Other Writings 19721977. Vintage.

Freire, P. (1970). Pedagogy of the Oppressed (M. B. Ramos, Trans.). Continuum.

Gender Education and Advocacy, I. (2001). Gender Variance: A Primer. Retrieved March 9, 2020 from http://www.gender.org/resources/dge/gea01004.pdf

Giffort, D. M. (2016). The Relationship Between Medical Education and Trans Health Disparities: A Call to Research. Sociology Compass, 10, 999-1013.

Grant, J. M., Mottet, L. A., \& Tanis, J. (2011). Injustice at EveryTurn: A Report of the National Transgender Discrimination Survey.

Hollander, J. A. (2013). Accountability, Interaction, and Gender Change. Gender \& Society, 27(1), 5-29.

hooks, b. (1994). Teaching to Transgress: Education as the Practice of Freedom. Routledge.

James, S. E., Herman, J. L., Rankin, S., Keisling, M., Mottet, L., \& Anafi, M. (2016). The Report of the 2015 U.S. Transgender Survey.

Johnson, E. P. (2016). Put a Little Honey in My Sweet Tea: Oral History as Quare Performance. WSQ: Women's Studies Quarterly, 44(3 \& 4), 51-67.

Lurie, S. (2005). Identifying Training Needs of Health-Care Providers Related to Treatment and Care of Transgendered Patients: A Qualitative Needs Assessment Conducted in New England. International Journal of Transgenderism, 8(2-3), 93- 
112.

Mertens, D. M., Bledsoe, K. L., Sullivan, M., \& Wilson, A. (2015). Utilization of Mixed Methods for Transformative Purposes. In A. Tashakkori \& C. Teddlie (Eds.), SAGE Handbook of Mixed Methods in Social \& Behavioral Research (pp. 193-214). SAGE Publications, Inc.

Mertens, D. M., Fraser, J., \& Heimlich, J. (2008). M or F?: Gender, Identity, and the Transformative Research Paradigm. Museums \& Social Issues, 3(1), 81-92.

Meyer, I. H., Brown, T. N. T., Herman, J. L., Reisner, S. L., \& Bockting, W. O. (2017). Demographic Characteristics and Health Status of Transgender Adults in Select U.S. Regions: Behavioral Risk Factor Surveillance System, 2014. American Journal of Public Health, 107(4), 582-589.

Neto, R. R., Hintz, F., Krege, S., Rübben, H., \& vom Dorp, F. (2012). Gender Reassignment Surgery - A 13 Year Review of Surgical Outcomes. International Braz J Urol 38(1), 97-107.

O'Cathain, A., Murphy, E., \& Nicholl, J. (2010). Three Techniques for Integrating Data in Mixed Methods Studies. BMJ, 341, c4587.

Petersen, S. K. (2008). Empowerment-inspired Patient Education in Practice and Theory. European Diabetes Nursing, 5(3), 99-103.

Poceta, J., Cousins, S., Wenzel, C., Lakhardt, K., Hojilla, C., Marlowe, L., Ayoob, J., Ritterman Weintraub, M., \& Zaritsky, E. F. (2019). Effectiveness of a Gender Affirming Surgery Class for Transgender and non-binary Patients and their Caregivers in an Integrated Healthcare Setting. International Journal of Transgenderism, 20(1), 81-86.

Romm, N. R. A. (2015). Reviewing the Transformative Paradigm: A Critical Systemic and Relational (Indigenous) Lens. Systemic Practice and Action Research, 28, 411427.

Sevelius, J. M., Deutsch, M. B., \& Grant, R. (2016). The Future of PrEP Among Transgender Women: the Critical Role of Gender Affirmation in Research and Clinical Practices. Journal of the International AIDS Society 19(756), 21105.

Shuster, S. M. (2017). Punctuating Accountability: How Discursive Aggression Regulates Transgender People. Gender \& Society, 31(4), 481-502.

Spade, D. (2003). Resisting Medicine, Re/modeling Gender Berkeley Women's Law Journal, 18, 15-23. 
Spade, D. (2015). Administrating Gender. In Normal Life: Administrative Violence, Critical Trans Politics, \& the Limits of the Law. Duke University Press.

Sprague, L., Afifi, R., Ayala, G., \& Lumuba El-nasoor, M. (2019). Participatory Praxis as an Imperative for Health-related Stigma Research. BMCMedicine, 17(32).

van de Grift, T. C., Elaut, E., Cerwenka, S. C., Cohen-Kettenis, P. T., \& Kreukels, B. P. C. (2017). Surgical Satisfaction, Quality of Life, and their Association After GenderAffirming Surgery: A Follow-up Study. Journal of Sex \& Marital Therapy, 44(2), 138-148.

Vargas, J. H. (2008). Activist Scholarship: Limits and Possibilities in Times of Black Genocide. In C. Hale (Ed.), Engaging Contradictions: Theory, Politics, and Methods of Activist Scholarship (pp. 164-182). University of California Press.

Winkle-Wagner, R., Lee-Johnson, J., \& Gaskew, A. N. (2019). Thinking with Queer of Color Critique: A Multidimensional Approach to Analyzing and Interpreting Data. In Critical Theory and Qualitative Data Analysis in Education. Routledge. 


\section{Appendix A. GAS - Patient Education Classes Feedback and Evaluation Form}

\section{OHSU Transgender Health Program/Kaiser Permanente Gender Pathways Clinic Gender Affirming Surgery-Patient Education Classes \\ Feedback and Evaluation}

1. Why did you participate in today's event (check all that apply)?

I wanted to learn about the topic

I am a current/prospective patient

I am a support person for a current/prospective patient

I am a health practitioner

Other (please specify):

2. What did you like about today's class (check all that apply)?

Meeting the surgeon and hearing about his background, technique, etc.

Learning more about how to prepare for surgery

Learning more about recovery from surgery

Hearing from patients who have had this surgery (if applicable)

Other (please specify):

3. How did you hear about today's class (check all that apply)?

My health care provider

Social media (Facebook, etc.)

Word of mouth

Transgender Health Program website

Other (please specify):

4. Where else would you like to see future classes advertised or promoted? 
5. If you are a current/prospective patient, were you able to get your questions answered today?

$\square$ Yes

$\square$ No

$\square$ If no, please list question here:

6. Overall, my experience of the class was:

$\begin{array}{ll}\square & \text { Excellent } \\ \square & \text { Good } \\ \square & \text { Neutral } \\ \square & \text { Fair } \\ \square & \text { Poor }\end{array}$

7. What suggestions do you have to improve this class?

8. What topics would you like to see at future classes?

9. What was the most important thing that you learned at today's class?

10. Please offer any other feedback/suggestions: 
Please share your name and contact information if you would like to discuss your experience further and/or provide input for future classes. 


\section{Appendix B. Participant Screening Tool for Qualitative Interviews}

\section{Confidential}

OHSU THP Patient Education Class Project - Participant Survey

Thank you for taking time to complete this survey!

Please fill out the following questionnaire if you would like to participate in the interviews for the THP Gender-Affirming Surgery Patient Education class curriculum project.

Note: We are collecting demographic information in order to learn from a variety of perspectives for this project. Information collected from this survey is strictly for recruitment and scheduling purposes.

If you have any questions or would like additional information about this project, please contact:

Shammarie Mathis (mathis@ohsu.edu)

Name

Legal name (if different):

My pronouns:

Email address

Phone number

Preferred method of contact:

Email

Phone call

$\square$ Text

If phone is preferred, can we send text messages or leave voicemails to coordinate scheduling?

QYes

○No

What gender-affirming patient education class did you attend?

Phalloplasty/Metoidioplasty

Vaginoplasty/Nulvaplasty

Other

$\square$ I have not attended a patient education class

Other class

04/05/2021 10:23am 


\section{Appendix C. Phase 2 Qualitative Interview Guide}

\section{Part I: Background and Thoughts about Considering Surgery}

Welcome and thank you for participating in this interview. The purpose of this interview is to learn about your experience as a patient considering gender-affirming surgery. I would like to hear about your experience with gender-affirming care, patient education, as well as suggestions on how to improve the course content for the THP patient education classes on gender affirming genital surgery.

1. Tell me about your experiences in accessing gender-affirming care.

2. These next few questions will ask about your experience(s) receiving genderaffirming care.

a. Is there a time where you felt affirmed in your gender, as who you are as a person, while accessing gender-affirming care?

b. Are there any other parts of your identity that have affected your experience?

c. What does affirming care look like to you?

d. What are some of the challenging experiences that you have had in attempting to access gender-affirming care?

i. Ask about giving up and how they got/are getting through it.

3. How do you get information about different surgical options?

4. How do you know when you're prepared for surgery? What does that look like to you?

a. Aside from feeling prepared, what else is important for you to know when considering surgery?

5. I understand that hearing prior patients share stories about their surgical experience at OHSU is important for some prospective patients. To what extent is this important to you and why?

6. Learning about the surgeon's technique and experience, as well as having the opportunity to meet them is also important for some prospective patients. To what extent is this important to you and why?

7. Ideally, what do you need to feel like you are confident in your decision about surgery?

\section{Part II: Reflecting on Surgical Experience}

The next few questions are about your experience in preparing for/completing genderaffirming surgery at OHSU. I want to understand your experience in considering surgery, including your concerns, questions, and your expectations about surgery (and recovery?), [as well as your surgical experience]. For the next questions, think about what you have experienced thus far as someone who has considered having surgery. 
If have had surgery:

8. Now that you have had surgery, what's something you wished you knew before starting the process?

9. What was your biggest fear when considering surgery? When going into surgery?

10. What's one outcome of surgery that you didn't expect?

11. What advice would you offer to someone considering surgery?

12. Ask about support system.

\section{If have not had surgery:}

13. What is something you want to would like to know before undergoing surgery?

14. What are your biggest fears when considering surgery?

15. [If choosing not to undergo surgery]: What are your reasons for choosing not to have surgery?

a. Why would someone not have/choose not to have surgery?

16. We are aware that the pandemic has affected people's access to health care, has this been the case for you?

\section{Part III: Thoughts on Patient Education Classes}

The following questions are about gender-affirming patient education classes. I want to understand your experience in accessing educational resources as part of considering surgery, [including attending the THP Gender-Affirming Patient Education class].

\section{If taken the GAS Patient Education class:}

17. From the screener, I saw that you attended the THPGAS class. Can you tell me about your experience with it?

18. Why did you decide to take this class?

19. Did you feel as if the class helped prepare you for surgery? If so, how?

20. Did you learn anything new about surgical outcomes that was not addressed during your consultation? If so, what?

21. Now that you have attended the class, is there anything that you would still like to know? If so, what?

a. [If had surgery]: Now that you have had surgery, is there any information you wish the class had provided? If so, what?

b. [If not had surgery]: Is there any information that you wanted to know that was not part of the class? If so, what?

22. Would you suggest this class to others who are considering surgery? Why or why not?

23. Do you have any other feedback or thoughts about the class?

If not taken GAS Patient Education class:

24. What was your reason for not taking the THP GAS Patient Education class? 
1. [If choosing not to take the class]: What would have changed your mind about deciding to take the class?

2. [If tried to attend class]: Were there any difficulties or other barriers that you experienced in trying to access the class (e.g., time/location, registration process, no one to join them, concerns about privacy, etc.)? What were they and how did they affect your ability to attend the class?

1.[If mention mistrust, ask about]: Mistrust of information, concerns about privacy

\section{Question for all:}

25. What information would be helpful to learn in a class format?

a. Are there other educational formats or resources that you would prefer over a class format (e.g., support group)? If so, what are they and why would you prefer them over a class format?

b. To you, what would an ideal class look like?

26. What resources beyond what currently exists would be helpful for people?

\section{Part IV: Closing Questions}

These final questions are an opportunity for you to provide direct feedback for the THP, as well as OHSU surgeons providing gender-affirming care.

27. What would you like to tell the THP or surgeons to help them improve the class and services?

28. If you were the one doing this interview, are there questions that I should have asked that I didn't ask? 